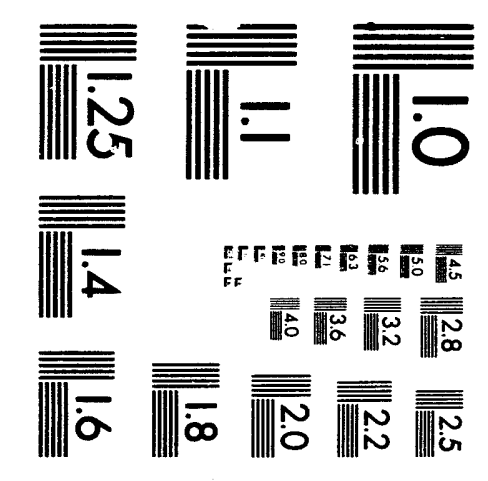



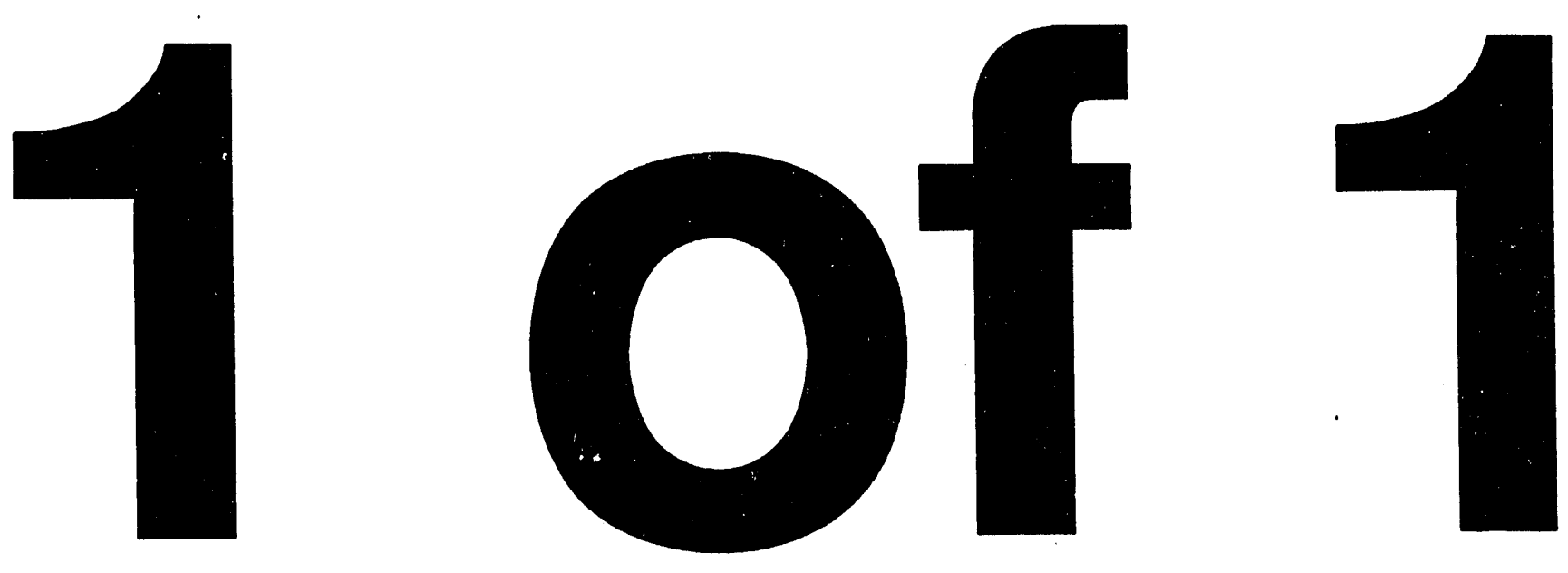


\section{Software Requirements Specification for the AREST Code Development}

November 1993

Prepared for the U.S. Department of Energy under Contract DE-AC06-76RLO 1830

Pacific Northwest Laboratory Richland, Washington 99352

(a) Martin K. Altenhofen, Waste Management Consultant 2000 Logston Boulevard, Richland, Washington 99352 


\section{Summary}

The Analysis of the REpository Source Term (AREST) computer code was selected in 1992 by the U.S. Department of Energy. The AREST code will be used to analyze the performance of an underground high level nuclear waste repository. The AREST code is being modified by the Pacific Northwest Laboratory (PNL) in order to evaluate the engineered barrier and waste package designs, model regulatory compliance, analyze sensitivities, and support total systems performance assessment modeling.

The current version of the AREST code was developed to be a very useful tool for analyzing model uncertainties and sensitivities to input parameters. The code has also been used successfully in supplying source-terms that were used in a total systems performance assessment (Eslinger et al. 1993). The current version, however, has been found to be inadequate for the comparison and selection of a design for the waste package. This is due to the assumptions and simplifications made in the selection of the process and system models. Thus, the new version of the AREST code will be designed to focus on the details of the individual processes and implementation of more realistic models.

This document describes the requirements of the new models that will be implemented. Included in this document is a section describing the near-field environmental conditions for this waste package modeling, description of the new process models that will be implemented, and a description of the computer requirements for the new version of the AREST code.

Process models that are being developed to enhance the current version of the AREST code include: 1) corrosion of the container, 2) oxidation of the spent fuel cladding, 3) oxidation and dissolution of the spent fuel, 4) dissolution of a glass waste form, 5) spatial and temporal variability of the waste package geochemistry, and 6) spatial and temporal transport through the waste package and into the host rock. 


\section{Contents}

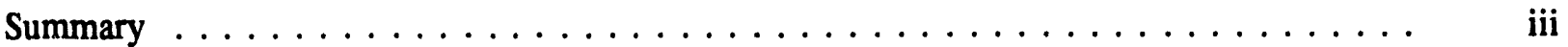

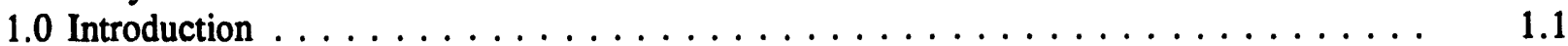

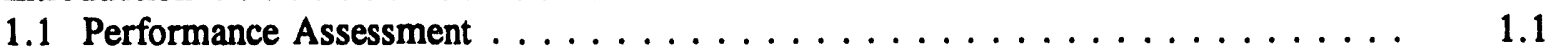

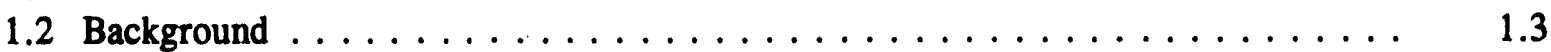

1.3 Description of New Model $\ldots \ldots \ldots \ldots \ldots \ldots \ldots \ldots \ldots \ldots \ldots$

1.4 Report Organization . . . . . . . . . . . . . . . . . . 1.6

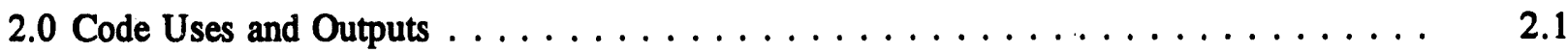

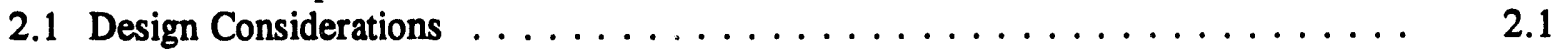

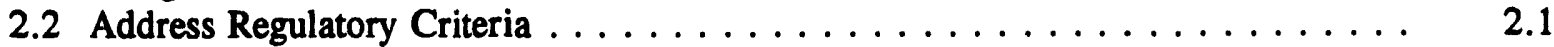

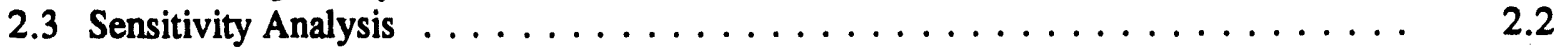

2.4 Total Systems Performance Assessment . . . . . . . . . . . . . . . . . 2.4

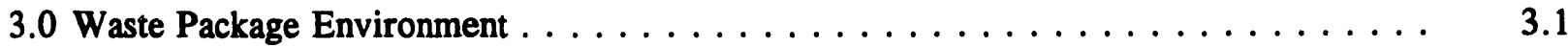

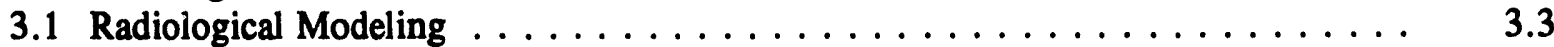

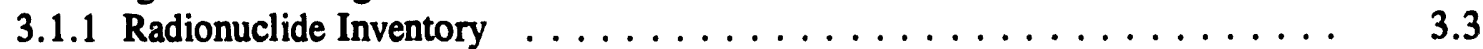

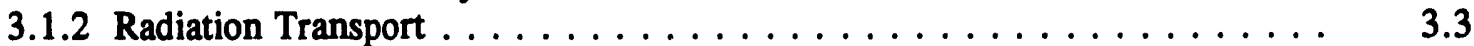

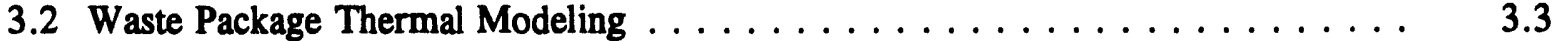

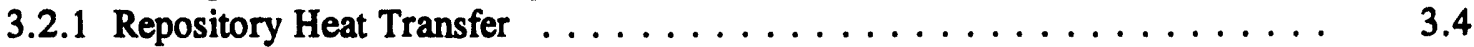

3.2.2 Waste Package Heat Transfer . . . . . . . . . . . . . . . . . . . 3.4

3.3 Near-Field Hydrologic Modeling . . . . . . . . . . . . . . . . . . . . . 3.4

3.4 Mechanical Modeling . . . . . . . . . . . . . . . . . . . . . . 3.5

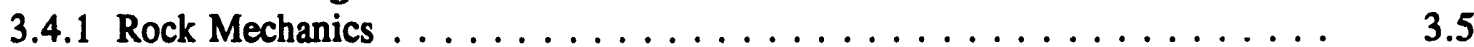

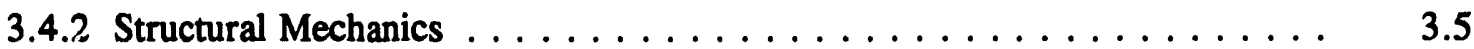

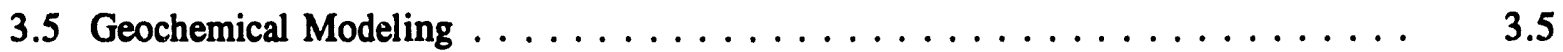

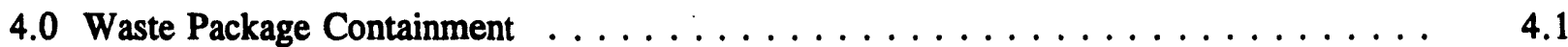

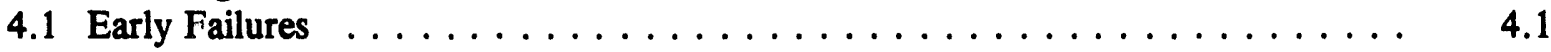

4.2 Corrosion Modeling $\ldots \ldots \ldots \ldots \ldots \ldots \ldots \ldots \ldots \ldots \ldots \ldots \ldots$

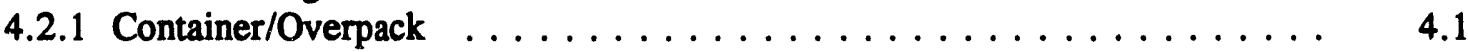

4.2.1.1 Operational Features . . . . . . . . . . . . . . . 4.3

4.2.1.2 Model Parameter Uncertainties . . . . . . . . . . . . . . 4.3

4.2.1.3 Model Outputs . . . . . . . . . . . . . . . . 4.4

4.2.1.4 Special Considerations $\ldots \ldots \ldots \ldots \ldots \ldots \ldots . \ldots \ldots$

4.2 .2 Cladding $\ldots \ldots \ldots \ldots \ldots \ldots \ldots \ldots \ldots \ldots \ldots \ldots \ldots \ldots \ldots$

4.3 Failure Distributions $\ldots \ldots \ldots \ldots \ldots \ldots \ldots \ldots \ldots$

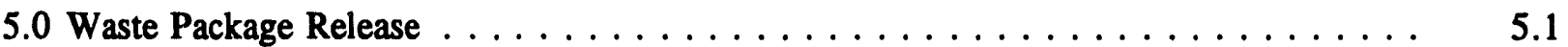

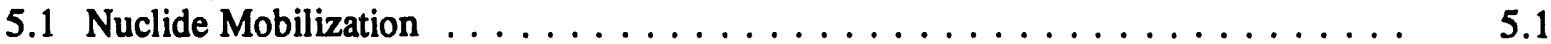

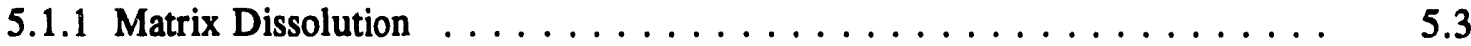

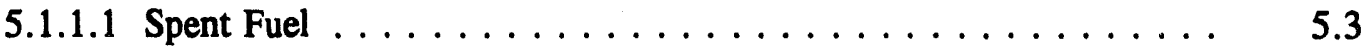

5.1 .1 .2 Glass $\ldots \ldots \ldots \ldots \ldots \ldots \ldots . \ldots \ldots \ldots$

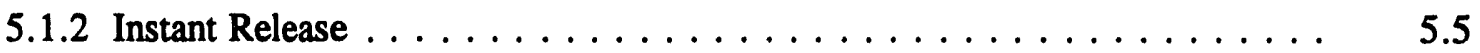

5.1.2.1 Spent Fuel Gap/Grain Boundaries . . . . . . . . . . . . 5.5 


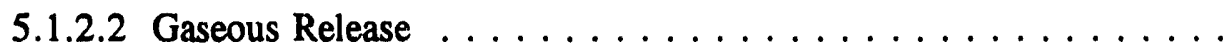

5.1.2.3 Vapor Phase Hydration . . . . . . . . . . . . .

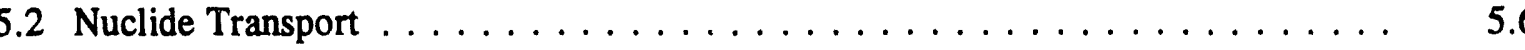

5.3 Colloid Transport $\ldots \ldots \ldots \ldots \ldots \ldots \ldots \ldots \ldots \ldots$

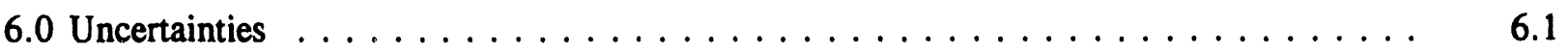

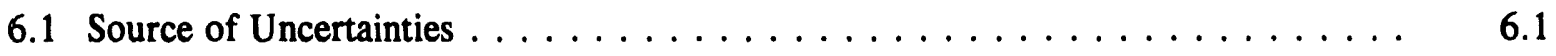

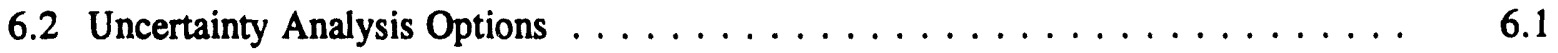

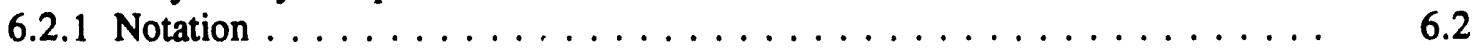

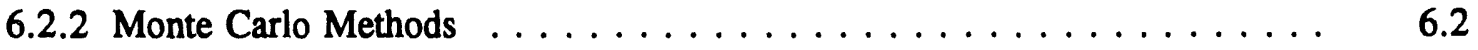

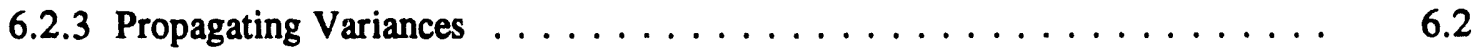

6.3 Code Requirements for Uncertainty Analyses . . . . . . . . . . . . 6.3

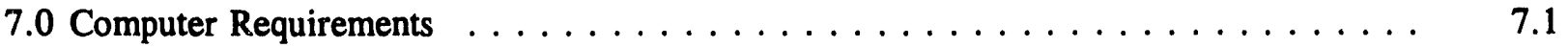

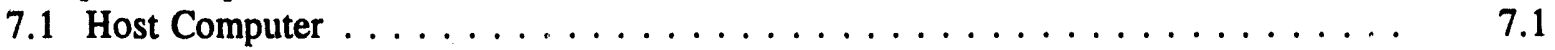

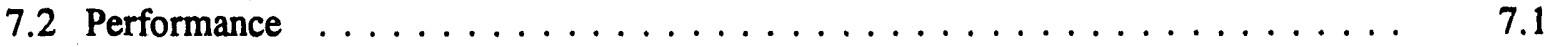

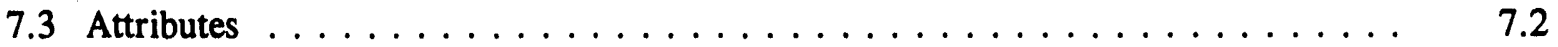

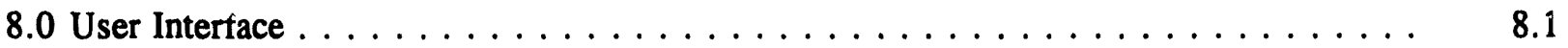

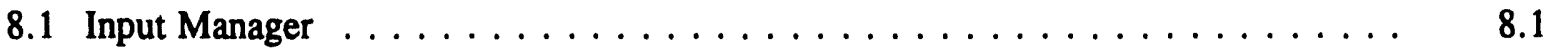

8.2 Plot Manager $\ldots \ldots \ldots \ldots \ldots \ldots \ldots \ldots \ldots \ldots \ldots \ldots \ldots \ldots$

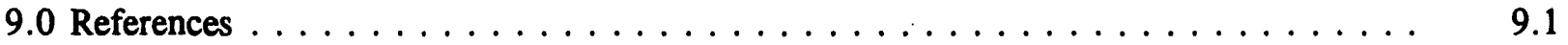




\section{Figures}

1.1 Levels of Model Development and Analyses for a Typical Performance Assessment . . .

1.2 Engineered Barrier Subsystem Defined for the AREST Code, Including Concepts,

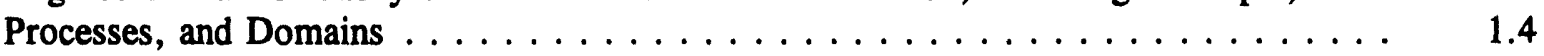

1.3 Waste Package Geometry for the Next Generation of the AREST Code $\ldots \ldots \ldots \ldots$

2.1 Overall Structure of the AREST Code for Modeling the Waste Package Domain . . . . 2.3

2.2 Overall Structure of the AREST Code for Modeling the Engineered Barrier Subsystem . $\quad 2.4$

3.1 Coupled Near-Field Environmental Processes $\ldots \ldots \ldots \ldots \ldots \ldots \ldots \ldots \ldots$

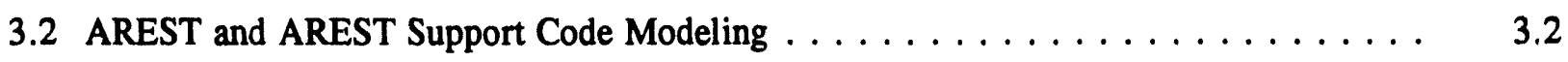

4.1 Overall Structure of the Waste Package Containment Process . . . . . . . . . . 4.2

5.1 Overall Structure of the Waste Package Release Process $\ldots \ldots \ldots \ldots \ldots$

5.2 Structure of the Waste Form Surface Concentration Module $\ldots \ldots \ldots \ldots \ldots$ 


\subsection{Introduction}

The U.S. Department of Energy (DOE) has assigned the task of managing and integrating the performance assessment studies at the proposed site for the underground nuclear waste repository at Yucca Mountain to the Civilian Radioactive Waste Management System (CRWMS) Management and Operating Contractor (M\&O). The M\&O has selected the AREST code as the waste package model for analyzing the engineered barrier system (EBS) of the repository (Van Luik et al. 1992). The AREST code was developed for the DOE at the Pacific Northwest Laboratory ${ }^{(a)}$ (Liebetrau et al. 1987).

Within the next few years, the Yucca Mountain Site Characterization Project Office (YMP) will be examining alternative EBS concepts that cannot be analyzed with the current version of the AREST code or any other existing DOE model. The current AREST code relies on relatively simple analytical models to describe release and transport of radionuclides from the waste package of the EBS. While these models provide necessary insights into near-field performance, many key processes are necessarily simplified or ignored. Consequently, a fundamental restructuring of the AREST code is needed to implement robust but computationally efficient models for the EBS and waste package performance assessment.

This document describes the software requirements specifications (SRS) for the next version of the AREST code. The document has been structured to describe the new modeling capabilities for the AREST code, based on the capabilities of the current, 1992 version (Engel and McGrail 1993). An SRS document is the first step in the development or modification of a computer code. This document is intended to facilitate agreement on the capabilities of the code by both the developer and the user/client. The mathematical formulations and the design of the software will be initiated after this document is completed. Code development will start following the completion of the mathematical formulations. It is understood by the authors that developing software requirements should be an iterative process. However, it should also be understood that after the design and coding tasks are started, revisions to the requirements will be more costly, in time and money.

\subsection{Performance Assessment}

Performance Assessment (PA) is a method to compare the predicted characteristics of a physical system against a standard or performance measure. For example, the U.S. Nuclear Regulatory Commission (NRC) specifies a fractional release rate requirement of $10^{-5}$ parts/year (release rate normalized by its 1000 year inventory) from the EBS for most nuclides (NRC 1983). A goal of a PA is to estimate fractional release rates from the EBS and compare the results to this criterion.

The PA process consists of different levels of analyses and detail. Figure 1.1 depicts the levels of the analyses represented by a pyramid. The base of the pyramid consists of models for individual

(a) Pacific Northwest Laboratory is a multiprogram national laboratory operated for the U.S. Department of Energy by Battelle Memorial Institute under contract DE-AC06-RLO 1830. 
mechanisms, e.g., pit initiation, oxidation, hydrolysis, sorption, speciation, precipitation, etc. Analyses with these models can give insight into the sensitivity of the individual mechanisms to specific input parameters. For implementation in a performance assessment code like AREST, the mechanism-specific models tend to be relatively simple analytical or numerical approximations to the equations governing the physics and/or chemistry of the mechanism.

In the next level up on the pyramid the mechanistic models are combined into conceptual models describing individual processes, e.g., pitting corrosion, uniform corrosion, stress corrosion cracking, dissolution, diffusion, retardation, etc. Process models can be treated individually or combined to analyze corrosion of a container material, for example. Sensitivity and uncertainty analyses can also be used to determine the importance of specific system parameters that affect the process. Realistic representation of these processes may result in a set of governing equations that requires a numerical method for solution.

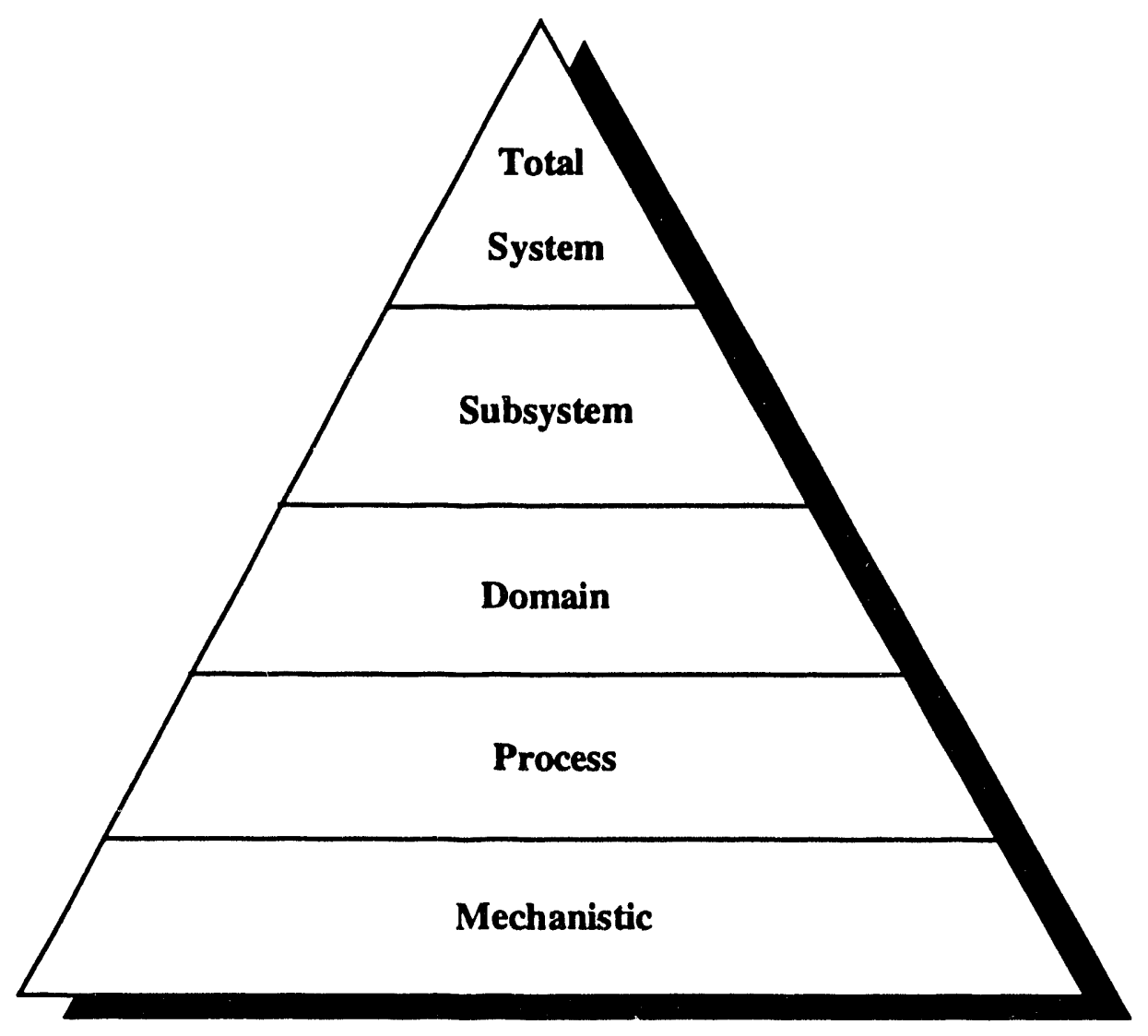

\section{MODEL HIERARCHY}

Figure 1.1. Levels of Model Development and Analyses for a Typical Performance Assessment 
The next level on the pyramid, illustrated in Figure 1.1, is the domain level. At this level the process models are combined to analyze a single domain, e.g., a waste package. Results from the domain model can be compared againsı a performance measure, e.g., the expected lifetime of the waste package. The domain model will contain all of the relevant mechanistic and process-level models. Unless many simplifying assumptions are made at the mechanism and process-level, solving a domain-level problem requires a numerical solution method.

The subsystem model is the next level progressing up the pyramid. This model combines the different domains into a subsystem of the total system, e.g., the waste package and the repository domains are combined to form the engineered barrier subsystem. By the time we get to this level, the detailed conceptual and process models are typically simplified. Simplifications are required because of current computational and input data limitations to realistically model a large number of waste packages over a large, heterogeneous spatial domain. Subsystem models tend to use distributions, response surfaces, and analytical models of simplified geometry and boundary conditions.

Finally, the top of the pyramid corresponds to the total systems-level model. At this level, all subsystems are combined into the high-level system, which for our modeling is a mined geological disposal system for the storage of nuclear waste. The models that make up the total systems-level model are typically simplifications of the domain and subsystem models. The total system model is generally used for repeated sampling of each subsystem.

Figure 1.2 lists the domains, processes, and concepts that will be modeled with the new version of the AREST code. The EBS is broken into the repository domain and the waste package domain. The repository domain will be modeled external to the AREST code and input as boundary conditions for the waste package domain. The AREST code will be designed for a detailed analysis of the waste package domain. Models will be incorporated for all of the components listed in Figure 1.2. If verifiable/defensible models do not currently exist for any of these components or processes, place holders will be implemented so that appropriate models can be added in the future. The domains, processes, and concepts are described throughout this document.

\subsection{Background}

The current version of the AREST code is based on a series of analytical models (Chambre et al. 1985) and a simple one-dimensional finite-difference numerical model (Grindrod et al. 1991) for calculating nuclide transport to the host rock. Constant boundary conditions are assumed at the waste form surface and chemical properties of the groundwater and EBS materials that affect nuclide migration are held fixed. The current version also includes a sophisticated graphical user interface to simplify and organize problem setup, and provide visualization of the computational results (Nakamura and Wilkins 1992).

The analytical models used in the AREST code have proven to be extremely useful tools for analyzing waste package performance and have recently been extended to incorporate a geochemical model for glass waste form dissolution (McGrail and Engel 1992). However, in the next few years, the DOE is planning on using the AREST code for detailed analyses of EBS designs, regulatory compliance assessments, and benchmarking against Total Systems Performance Assessment (TSPA) 


\section{Engineered Barrier Subsystem}

\author{
Repository Domain \\ - heat transfer process \\ - geochemical process \\ - geomechanical process \\ - liquid/gas flow process \\ - liquid/gas transport process
}

Waste Package Domain

- waste package environmental process

temperature

saturation

rock stress

groundwater composition

radionuclide solubilities

- waste package containment process

$$
\begin{aligned}
& \text { pre-failures } \\
& \text { container failure } \\
& \text { uniform corrosion } \\
& \text { stress corrosion } \\
& \text { pitting corrosion } \\
& \text { crevice corrosion } \\
& \text { cladding failure }
\end{aligned}
$$

- waste package release process

$$
\begin{aligned}
& \text { spent fuel dissolution/oxidation } \\
& \text { glass dissolution } \\
& \text { gaseous release } \\
& \text { transport through partially failed container } \\
& \text { transport through backfill } \\
& \text { transport through disturbed rock } \\
& \text { transport into rock }
\end{aligned}
$$

Figure 1.2. Engineered Barrier Subsystem Defined for the AREST Code, Including Concepts, Processes, and Domains

codes. The process models that are currently implemented in the AREST code are inadequate for these functions. In part, the models are inadequate because of the special conditions of the unsaturated site at Yucca Mountain. In addition, the models are design specific rather than being flexible enough to test alternative design concepts.

The simplified treatment of critical chemical processes, in the current version of the AREST code, that affect containment and radionuclide release and migration must be addressed if the DOE is to have a reliable and defensible model for waste package PA analyses. For example, chemical retardation depends on a variety of solution and solid chemical properties, and a constant retardation factor is known to be inappropriate for modeling solute transport in geologically complex systems (Reardon 1981; Serne and Muller 1987). Yet the current version of the AREST code and other PA codes use fixed $K_{d}$ values that have bcen demonstrated to give non-conservative breakthrough times 
by as much as $10^{4}$ years for several key radionuclides (Pescatore and Sullivan 1985). In our 1992 study (McGrail and Engel 1992), we demonstrated that chemical changes in groundwater chemistry resulting from glass dissolution can significantiy affect the solubilities of key actinide elements. Also, decay-chain ingrowth in the buffer surrounding a waste package has been shown to cause the development of precipication fronts. None of these important processes can be addressed with the current version of the AREST code.

Another key area that needs to be upgraded in the AREST code is containment modeling. Loss of containment is now modeled using a realization from a statistical distribution or simply assumed when the waste package temperature drops below the boiling point of water. Additional data are becoming available that may permit taking into account a partially-failed container or zircaloy cladding as a barrier to release and transport.

The new version of the AREST code will be designed to address all of the above issues, limited primarily by the availability of reliable data and in some instances the availability of mechanistic models. Additional details on the proposed capabilities for the new AREST code are given below.

\subsection{Description of New Model}

The new version of the AREST code will be designed for internal simulation of processes that affect container and cladding corrosion, radionuclide mobilization, and mass transport. In particular, a geochemical model will be coupled with a transport model and the resulting system of differential and algebraic equations will be solved both spatially and temporally. However, several environmental processes will be assumed to be independent of the corrosion, dissolution, and transport processes. Examples include radiolysis, rock mechanics, heat transfer, and water infiltration. Each of these processes will be modeled external to the AREST code with detailed support codes. Results from the external codes will be input into the AREST code as parameters or as initial and boundary conditions.

While it is possible to couple the heat equation with Darcy's law to calculate the effect of temperature on fluid and heat flow, we assume that corrosion and solute transport have little influence on heat transfer and fluid flow and thus there is no need to couple these processes into the transport solver. (a) Similar rationale about the lack of strong cross coupling is made for other waste package processes, such as radiolysis and rock mechanics, to justify their exclusion from direct solution in the AREST code.

The AREST code will contain the capability to model two different barriers that affect waste package containment failure time, including several types of container materials. The first barrier will be the container/overpack. Several corrosion mechanisms will be modeled including uniform corrosion, stress corrosion cracking, pitting corrosion, and intergranular attack. The second barrier

(a) Modeling changes in fluid flow arising from changes in porosity and permeability of the host rock or backfill may need to be taken into account in the future once an adequate relationship that defines such changes as a function of temperature and mineral dissolution/precipitation is available. 
will be the cladding surrounding the spent fuel. Several tasks within the YMP are underway that are evaluating cladding corrosion and failure mechanisms. As models are developed from these tasks, they will be incorporated in the AREST code.

Containment modeling using the AREST code will maintain the current level of flexibility. The user will have the option to select mechanistic (if available), semi-empirical, or response surface models to analyze both barriers. The user will also have the option to select failure times based on a user supplied probability distribution. Failure times will also be modeled based on environmental parameters, e.g., failure can occur when waste package temperatures drop below the boiling point and water can reenter the system.

Numerical models will be developed to predict mass transport of solutes through a partially failed container, through a crushed tuff or a clay backfill, through a disturbed rock zone, and finally into a fractured host rock. Spatial discretization will be set on a two-dimensional orthogonal grid with a possibility of extending the scheme to a three-dimensional non-orthogonal grid in a future version. The models will account for solubility constraints, radionuclide decay, and decay chain ingrowth at each node and time step throughout the EBS. Figure 1.3 displays an example of the twodimensional geometry which will be available with the next version of the AREST code.

The new transport model will be capable of solving multicomponent solute transport problems coupled with equilibrium and/or kinetically-controlled chemical reactions in partially saturated media. Although provisions for a $K_{d}$ equivalent isotherm for treating sorption will be provided, the model will be generalized to include site-specific ion-exchange and surface complexation reactions. The required conditions such as the water flux and chemical composition of groundwater infiltrating a waste package will be provided from external analyses. In addition, saturation values for the host rock and the backfill as a function of temperature will be determined externally by a coupled thermalhydrologic model. This data will be used to derive effective diffusion coefficients for use in the transport calculations.

Uncertainties will be estimated for each prucess model: from container corrosion to waste form dissolution to transport into the host rock. Uncertainties in parameters obtained from experiments, i.e., parameters obtained by a regression analysis of experimental data, will be included. The process model uncertainties will then be propagated throughout the system where possible, limited by the complexity of the reactive transport model. The goal is to estimate release at any specified time with a single performance parameter (e.g., container failure time or average release rate) and an estimated uncertainty measure (i.e., a standard deviation or variance). Uncertainties for a PA analysis are generally estimated using the probabilistic total systems model. However, using detailed numerical models we can get an understanding of which processes, components, and parameters contribute most to the uncertainty.

\subsection{Report Organization}

This document is organized as follows: Section 1.0, this introduction, provides an overview and background on the AREST code development. Section 2.0 describes the uses, the outputs, and the overall structure of the next version of the AREST code. The waste package domain modeling for 


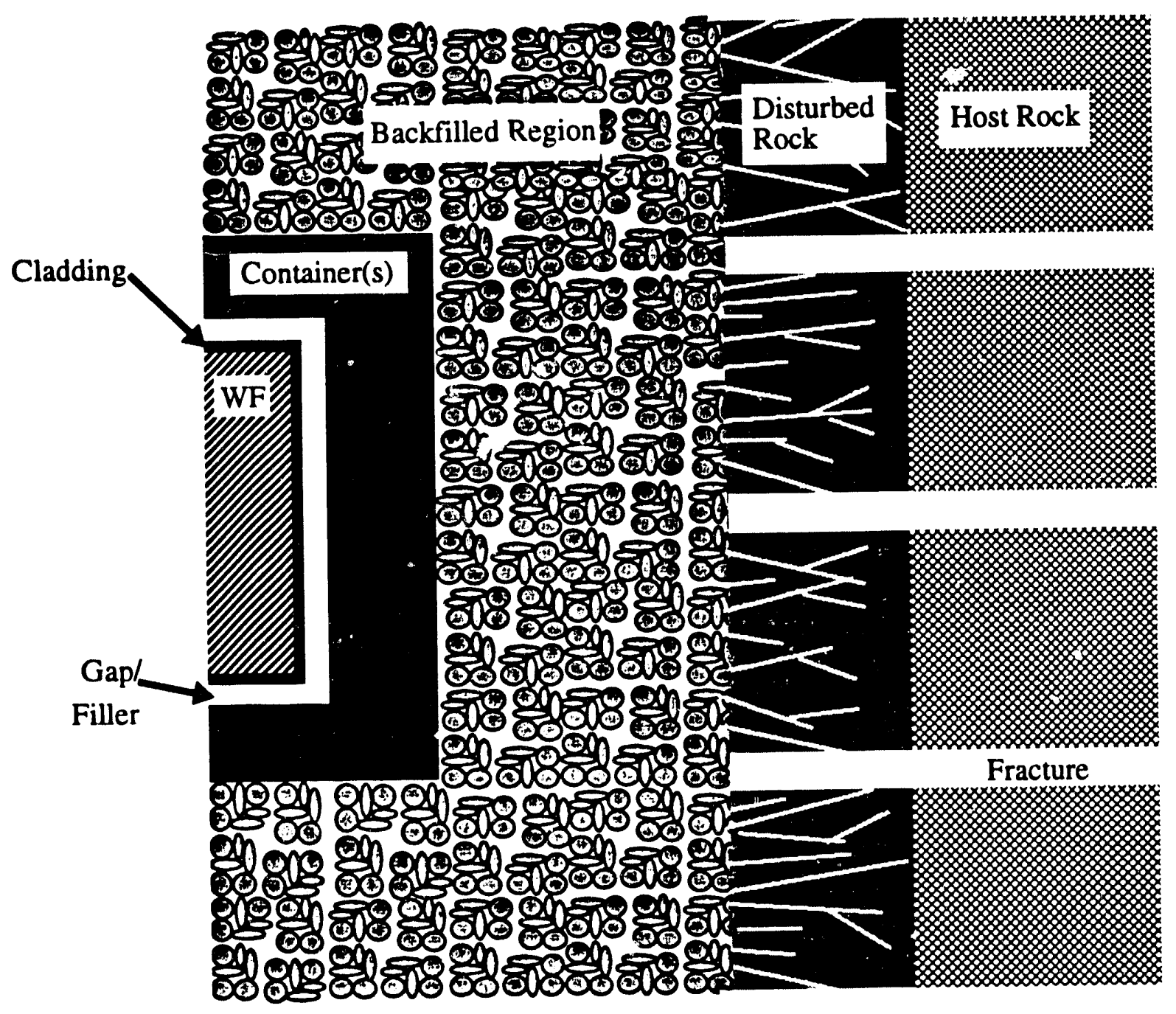

Figure 1.3. Waste Package Geometry for the Next Generation of the AREST Code

the AREST code is divided into three processes which are described in separate sections of this document. Section 3.0 describes the near-field environmental processes, Section 4.0 describes the waste containment failure process, and Section 5.0 describes the waste package release process. Section 6.0 discusses the uncertainty modeling for the new version of the AREST code. The computer requirements for the AREST code are discussed in Section 7.0, and the user interface is described in Section 8.0. 


\subsection{Code Uses and Outputs}

The new version of the AREST code will be designed for analysis at the process level and at the waste package domain level. However, capabilities for analysis of the engineered barrier subsystem will also be included. The overall structure of the AREST code is shown in Figures 2.1 and 2.2 and described later in this section. The specific uses of the code are listed below:

- evaluate EBS design

- model regulatory compliance

- analyze sensitivities

- support TSPA modeling.

\subsection{Design Considerations}

The AREST code will be developed with capabilities to evaluate different EBS designs. Capabilities for modeling different waste container materia's and dimensions, waste loading scenarios, and the effects of different backfill materials and dimensions will be provided. The process models that will be implemented will be realistic representations of the governing physical and chemical processes where possible. This philosophy is adopted so that analysis of EBS designs can be related to specific mechanisms or parameters that impact performance and to evaluate uncertainties in both the conceptual and process models.

The AREST code will be designed to perform separate detailed analyses of each component and process. This will allow for testing the results of each model as the input parameters or designs are varied. For example, capabilities for analyzing container corrosion separate from modeling transport will be provided. These analyses can be very useful when designing the container and simulating waste loading scenarios.

\subsection{Address Regulatory Criteria}

In order to qualify a potential site for use as an underground high-level waste repository, regulatory criteria will have to be addressed. Historically, the regulatory criteria which applied to the EBS modeling were 1) 10 CFR 60 (NRC 1983) and 2) 40 CFR 191 (EPA 1985). With the passage of the 1992 Energy Bill, October 1992, the requirements of 40 CFR 191 no longer apply to a potential repository at Yucca Mountain, Nevada. The National Academy of Sciences (NAS) was contracted to provide, by December 31, 1994, findings and recommendations on reasonable standards for protection of the public health and safety. The U.S. Environmental Protection Agency (EPA) has been given two years (until December 31, 1995) in which to promulgate a new standard and for setting general health and safety requirements, based upon and consistent with the findings and recommendations of the NAS. The NRC then has an additional year (until December 31,1996 ) in which to modify 10 CFR 60 to implement the new EPA standard. 
Although regulatory requirements are currently not fixed, we know that we must evaluate the release from the waste package/EBS in our PA analyses. Based on past regulatory criteria developed by the NRC and the EPA, the AREST code must be capable of supplying the following data:

- radionuclide flux as a function of space and time

- radionuclide concentration as a function of space and time

- cumulative fluxes

- radionuclide fractional release rates

- time-dependent container inventories

- waste container failure times

- uncertainty estimates for calculated results.

These results will be calculated at the domain level. The overall structure of the modeling at the domain level is illustrated in Figure 2.1. At the domain levol, each process (environmental, containment, and release) is modeled for each time step of the analysis. If the process is not active at a given time step, it will be ignored, e.g., release modeling is not active until the container has failed. Each process of the waste package domain is described later in separate sections of this document.

\subsection{Sensitivity Analysis}

Sensitivity analyses are an important part of a PA process. Using sensitivity analyses we try to quantify the relationship between the predictions of a model and its input parameters. We try to define those input variables that have the greatest influence on the results of the models. We also try to define the relevant ranges for the input parameters of our models given that we have predefined performance measurements to compare against.

The capability for doing sensitivity analysis exists in the current version of the AREST code. However, this capability will have to be enhanced to allow for sensitivity analyses at different levels of the PA process. Individual conceptual models will be exercised several times independently of the process models to measure sensitivity of the results due to uncertainty in the input parameters; e.g., each corrosion model will be analyzed separately to identify the parameters which have the biggest effect on the corrosion rate. Also, the process models will be exercised separately from the domain model to measure the sensitivity of the individual processes; e.g., the containment process will be analyzed to identify the key corrosion mechanisms.

Sensitivity analyses at the domain level are needed to identify and rank processes affecting waste package performance. For instance, changes in the time of failure may have little effect on the magnitude of the release rate from the waste package, whereas changes in the dissolution rate of the waste form could significantly effect the release rate of some radionuclides. For these analyses, sampling designs can reduce the number of runs while still producing a good estimate of sensitivity to the individual process. Thus we will enhance the current capability of the AREST code by implementing sampling designs (e.g., Latin Hypercube Sampling).

The output from a sensitivity analysis will be based on the type of analysis being done. For example, when estimating a failure time distribution to be used by a TSPA model, the output would 


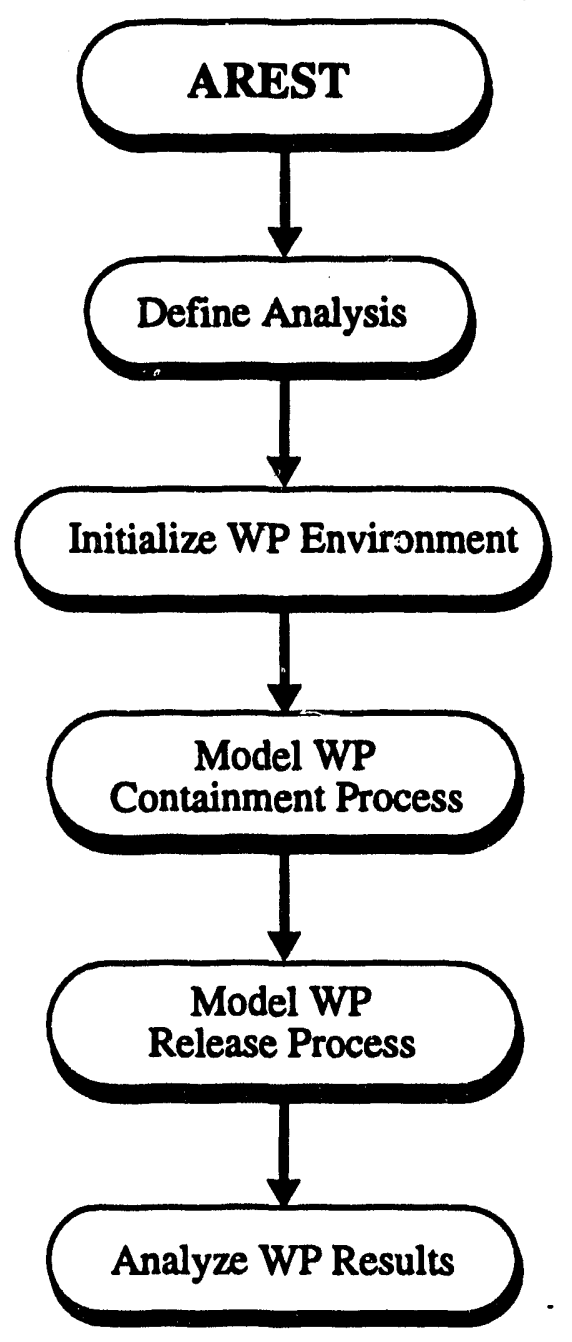

Figure 2.1. Overall Structure of the AREST Code for Modeling the Waste Package (WP) Domain

be the failure time for each run/analysis. However, if a response surface as a function of temperature and groundwater composition is going to be developed for the failure time, then the output needs to contain the parameters along with the failure time. The AREST code will be designed to allow the user to specifically identify which parameters to output when doing sensitivity analyses. For instance, the user might specify that the time of failure is the only output for the analysis, or the user might specify to output the failure time, the temperature, $\mathrm{pH}$, and $\mathrm{Eh}$ at the time of failure. This would allow a response surface to be fit to the results. 


\subsection{Total Systems Performance Assessment}

In performance assessment analyses for the total system, repeated sampling of scenarios and input parameters will be needed. The results of these anailyses will be used to construct a complementary cumulative density function (CCDF) of release to the accessible environment.

Constructing a CCDF could require hundreds of samples to be run, with different source-terms being calculated. It is not reasonable to use a detailed numerical model for this type of analysis. However, the AREST code will be designed to calculate source-term estimations for benchmarking and comparing results against results from a probabilistic TSPA source-term model (e.g., RIP: Kossik et al. 1992). The detailed models will also be used to create the data to construct response surfaces and distributions that can be used by the probabilistic TSPA source-term model.

The structure of the AREST code for use with the TSPA model is shown in Figure 2.2. The potential repository will be divided into groups. Each group will be represented by a single waste package, assuming a homogeneous distribution within each group. The results of each group will be combined to create the source-term for comparison and use by the total systems model. This type of subsystem-level modeling is needed to bridge the gap between the detailed modeling at the process and domain levels and the probabilistic modeling at the total systems level.

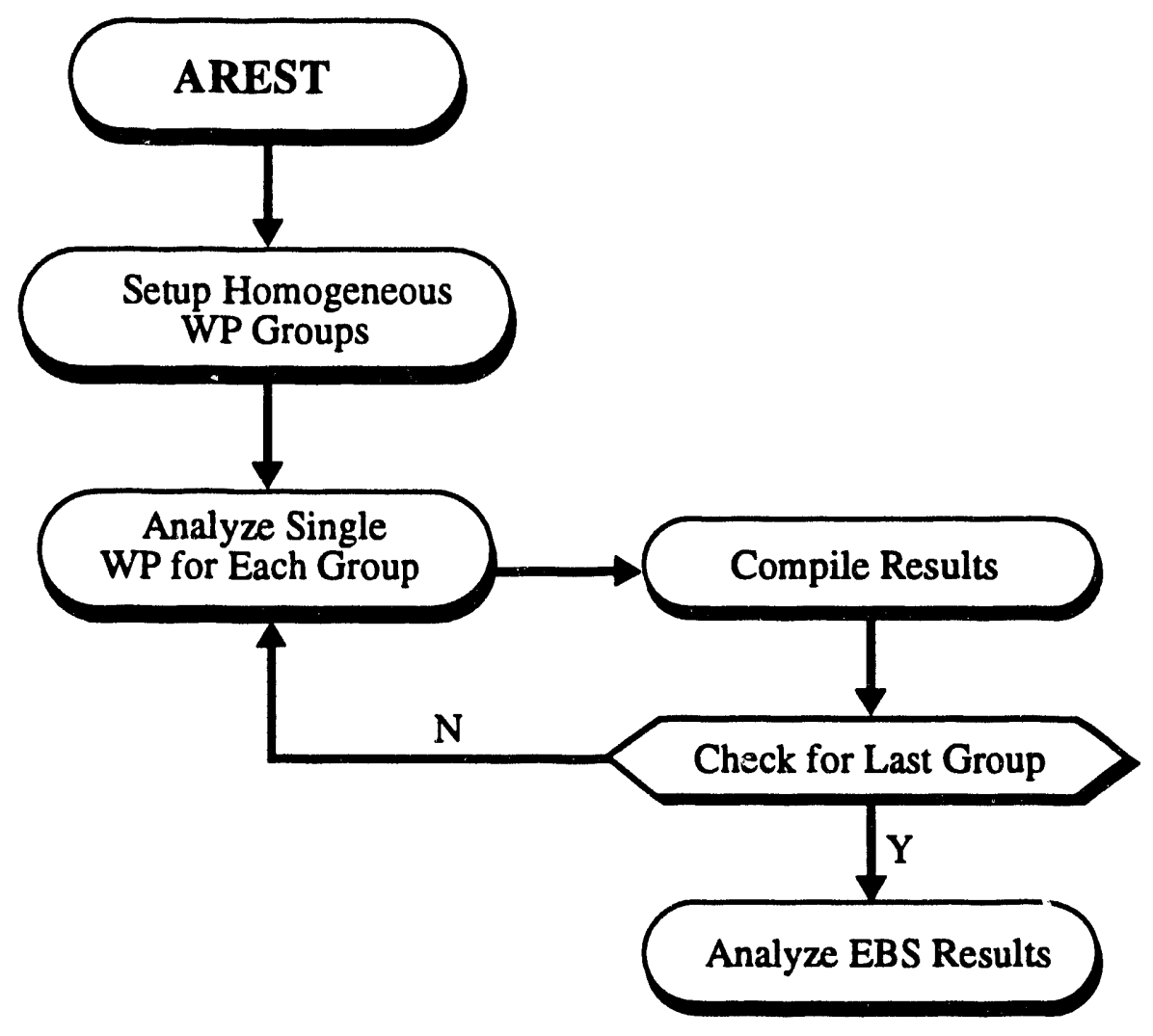

Figure 2.2. Overall Structi:e of the AREST Code for Modeling the Engineered Barrier Subsystem (EBS) 


\subsection{Waste Package Environment}

Engineered barrier system performance cannot be modeled with the AREST code without information that describes the near-field environmental conditions of the waste package. Figure 3.1 illustrates the coupling between processes in the near-field environment of the waste package. The solid arrows represent the coupling that will be modeled internal to the AREST code. The remaining coupling, dashed arrows, will be modeled externally in support code analyses.

The near-field computer codes that simulate the physical and chemical processes are complex and require extensive computing time. Therefore, it is not practical for all of these codes to be incorporated directly into the AREST code. The philosophy used to develop the AREST code is that many of the environmental processes can be decoupled from the waste package modeling, allowing them to be modeled external to the AREST code.

Process-specific codes can be used to simulate the near-field environment and provide information to the AREST code. The use of near-field support codes in this fashion preserves the computational efficiency of the AREST code without the loss of modeling accuracy that would result from the adoption of simplified models.

The AREST code will contain radiological, hydrothermal, thermal, mechanical, and geochemical input modules that are designed to link the near-field parameters with the main components of the AREST code. Figure 3.2 illustrates the support code data that are supplied by each model.

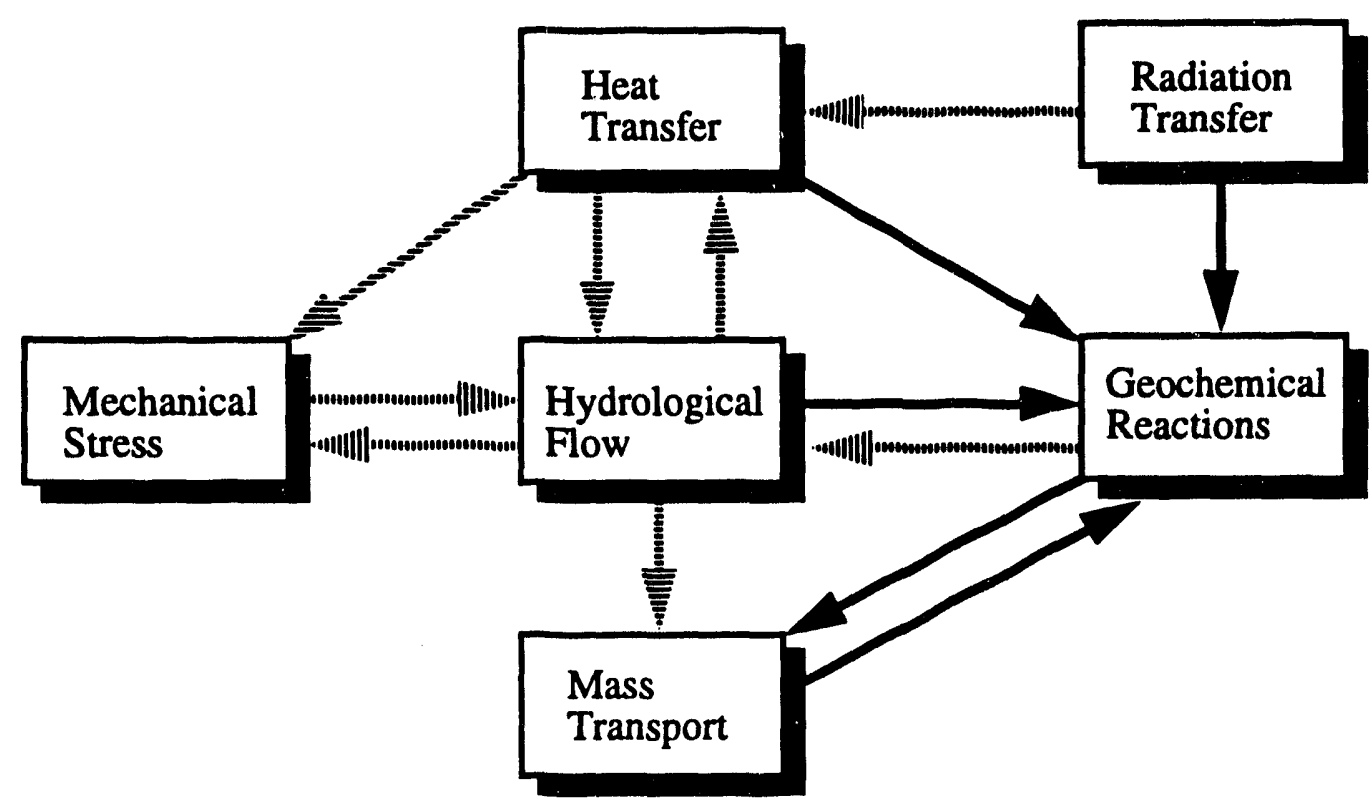

Figure 3.1. Coupled Near-Field Environmental Processes. Solid arrows imply models internal to the AREST code (after Wang et al. 1983). 


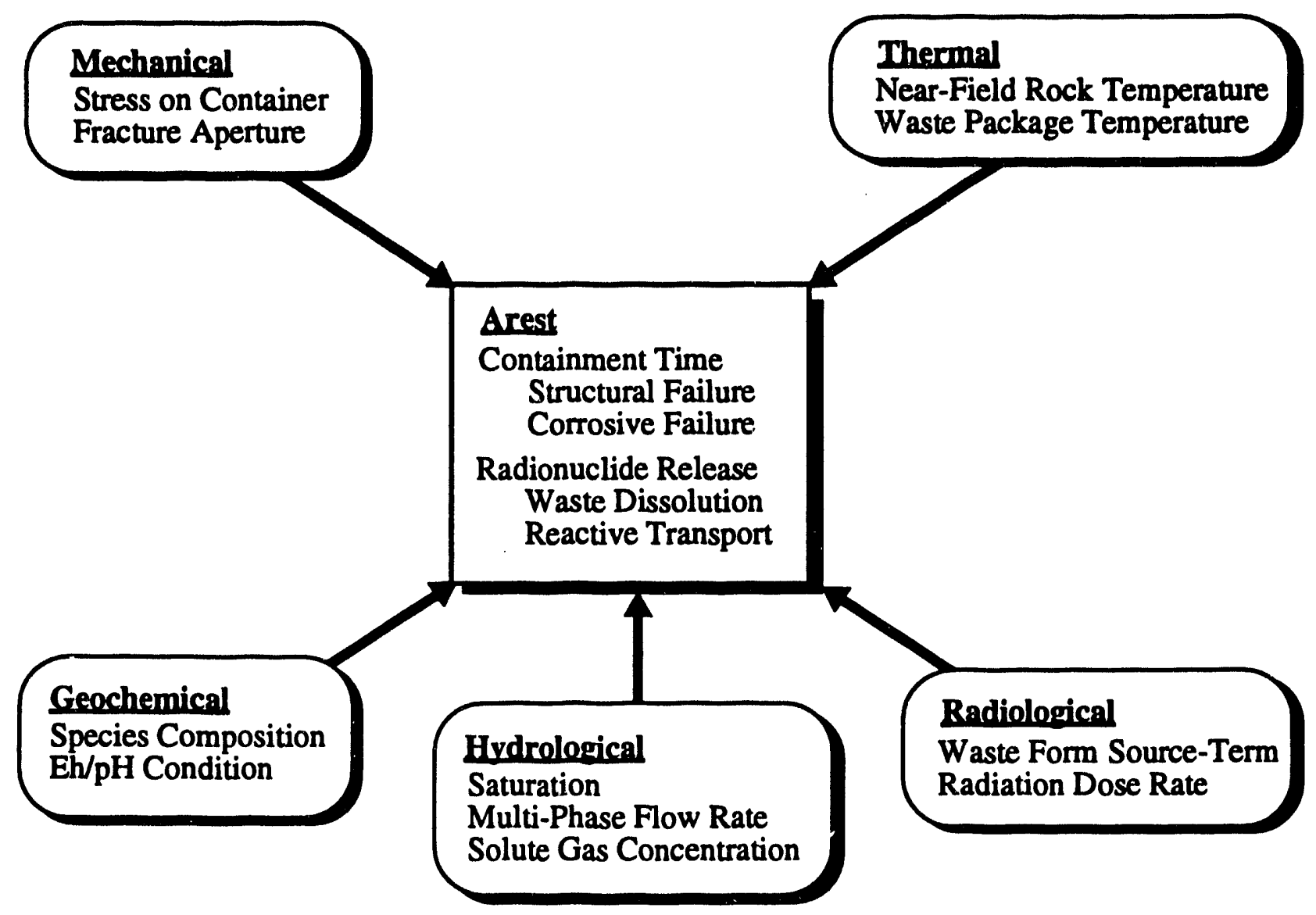

Figure 3.2. AREST and AREST Support Code Modeling

The output from the near-field support codes can be processed in a variety of ways for use by the AREST code. The AREST code interface may involve the development of a functional relationship or algorithm for interpolation and selection of parameter values during an analysis. The AREST code has and will be designed to input the processes and parameters that have a significant effect on waste package performance. Parameters may be represented by a functional relationship that describes the temporal and spatial variability in the repository system. For temperature dependent parameters, such as saturation, spatial variability can be simulated with a corresponding functional relationship or with tabular data that describes the effect of temperature on that parameter.

The following sections describe in more detail the data supplied by the environmental support codes and interfaces with the AREST code. 


\subsection{Radiological Modeling}

Radiological modeling is needed to evaluate the radionuclide inventory, decay heat characteristics of the waste package, and radiation transport. The heat generation rate and inventory characteristics are important for therrnal and radionuclide release modeling, while radiation transport is important for evaluating the effects of radiation damage to waste package materials. These processes are described below.

\subsubsection{Radionuclide Inventory}

Radionuclide inventory data and decay characteristics of spent fuel and high-level waste forms affect many waste package processes including containment and EBS release. A number of the decay characteristics are interrelated, such as inventory, burnup, and waste age for spent fuel. The parameters for the source-term for spent fuel and high level waste should include the timing and location of waste package emplacement and the necessary data to determine how the waste characteristics will change with isolation time.

The AREST code will input radionuclide inventories at the time of emplacement into the repository. The AREST code will then track inventories as a function of decay, ingrowth, and release. Heat generation rates will be used by the external thermal model for calculating waste package repository temperatures.

\subsubsection{Radiation Transport}

The radiation transport module will estimate the radiation dose in the waste package and surrounding host rock during waste isolation. The radiation dose information is needed to determine the effects of radiation damage to waste package materials and the effects of gamma and alpha radiolysis on waste-barrier-rock interactions. The radiation dose rate is dependent on the waste package design and the waste form source-term characteristics. The total absorbed dose, integrated over time, for a simulated waste package will be conservatively estimated by using a transfer function that is dependent on the radiation source-term characteristics and waste age at emplacement. The effect of the waste package degradation, including structural failure modes, will be incorporated in the radiation transport model. The AREST code will require information that describes the effect of gamma and alpha radiation dose on waste package material property damage, corrosion rate and dissolution rate enhancement, and radionuclide transport behavior.

\subsection{Waste Package Thermal Modeling}

The AREST code will utilize time-dependent temperatures calculated for the waste package, the waste container, and the waste form surface. The models required for calculating these temperatures will require, as boundary conditions, temperatures generated with repository-scale models external to the AREST code. The repository-scale and waste package scale models are described below. 


\subsubsection{Repository Heat Transfer}

Near-field host rock temperatures should be evaluated with a three-dimensional heat transfer model of the underground facility for the potential repository. The model should incorporate the actual waste emplacement configuration. The repository-scale model will be used to provide the boundary conditions for the waste package heat transfer model and also interface with the rock mechanics and the multi-phase groundwater flow models.

The objective of the thermal modeling is to evaluate the spatial and transient behavior so that variable thermal load conditions are accounted for in the AREST code. The area thermal load of the potential repository will be adjusted during waste emplacement to accommodate spent fuel receipts with variable age and burnup characteristics. Near-field temperatures are sensitive to the design and thermal loading of the potential repository, waste package heat generation, and thermal properties of the rock mass.

\subsubsection{Waste Package Heat Transfer}

The purpose of the waste package heat transfer model is to evaluate waste package component temperatures. The waste package component temperature histories are needed to evaluate the thermal processes associated with waste package containment and release performance. Waste form temperatures and waste container surface temperatures will be calculated external to the AREST code. The results of the detailed external support code analyses will be input into the AREST code via lookup tables. Component temperatures will be estimated based on heat loading and near-field temperatures at each time step.

\subsection{Near-Field Hydrologic Modeling}

The near-field environment surrounding the waste package will significantly affect container corrosion and radionuclide dissolution processes. A primary assumption associated with the AREST code, however, will be that container corrosion and radionuclide processes will be decoupled from the near-field hydrologic environment. This assumption allows the complex modeling of the hydrologic environment to be performed independently of the waste package model.

The AREST code will utilize both temporal and spatial temperature and saturation values, liquid and vapor flow rates, and relative humidity values. This data will be calculated externally and input into the AREST code as lookup tables. Conca and Wright have shown that some transport properties, e.g., diffusion coefficient and hydraulic conductivity, can be modeled as functions of the volumetric water content of the rock (Conca and Wright 1992).

Near-field hydrologic modeling conducted external to the AREST code should be done using a multi-phase flow component model. The purpose of the multi-phase flow component model is to calculate the air, water vapor, and liquid groundwater flow conditions in the engineered barrier system and the disturbed rock zone. It would be used to evaluate the extent and duration of near-field boiling conditions and to evaluate the multi-phase conditions following the initial waste emplacement 
and resaturation of the waste package. The initial environment is anticipated to be hydrologically unsaturated and chemically oxidizing.

\subsection{Mechanical Modeling}

Near-field mechanical process models are needed to determine the rock displacement in the disturbed rock zone and deformation in the waste package. The condition of the rock, fractured or unfractured, and the stress that the rock places on the waste package can be important when analyzing groundwater flow, radionuclide release, and corrosion processes. These results will be calculated externally and input into the AREST code as boundary conditions as described below.

\subsubsection{Rock Mechanics}

The external rock mechanics process model will calculate rock stresses and displacements in the disturbed rock zone surrounding the waste package. The disturbed rock zone should be modeled with a discontinuum rock stress code to determine the effects of the transient thermal conditions on the fracture characteristics, on the stability of the borehole or drift emplacement wall, and on the potential load conditions of the waste package. During the thermal period when boiling conditions are expected to occur, the fractures induced by the excavation and thermal stresses are expected to promote dehydration of the disturbed rock zone in contact with the waste package. For anticipated matrix-dominated groundwater flow conditions, the fractures may provide an effective diffusion barrier limiting radionuclide release from the waste package. Under fracture flow conditions, the disturbed rock zone may provide a preferential pathway for groundwater flow and radionuclide transport away from the waste package. This type of modeling is needed to characterize the fractures and to help define the needed discritization for the transport model.

\subsubsection{Structural Mechanics}

The structural mechanics process model will calculate the stresses in the waste package. These stresses will occur because of external loads, thermal expansion and gradients, volume expansion of corrosion products, residual stresses from waste package fabrication, mechanical and thermal stress, and unstable crack formation. A stress distribution in the waste package container will be used to predict stress-induced corrosion. The structural integrity of the waste package components will also be evaluated, including container buckling and compaction of gravel packing materials.

\subsection{Geochemical Modeling}

Near-field geochemistry and waste/barrier/rock hydrothermal interactions will be predicted as part of the coupled reactive transport model that is described in more detail in Section 5.0. However, the chemistry of the groundwater infiltrating the EBS is an important boundary condition needed for the reactive transport calculations. This data will be provided from a far-field analysis of isothermal rock-water interactions or from a hydrothermal model that accounts for the effects of boiling and precipitation as the wetting front collapses back on the waste package (Arthur and Murphy 1989). The AREST code will utilize the time-dependent groundwater composition calculated at the host rock boundary as a time-varying boundary condition for reactive transport simulations. 


$$
\longrightarrow
$$

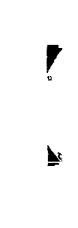

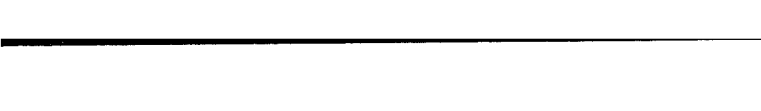




\subsection{Waste Package Containment}

The containment process describes the lifetime of the container barrier. The AREST code will contain three possible methods for modeling the loss of containment. The user will select the modeling method from the following list:

- early failures

- corrosion modeling using mathematical models

- simulation of failure times as a realization from a distribution.

\subsection{Early Failures}

Early failures and prefailures will be modeled using either statistical or user-supplied distributions. Release from a prefailed container will be limited to gaseous release. Release from the matrix will not occur until rewetting of the waste package has occurred.

\subsection{Corrosion Modeling}

This type of modeling pertains to the use of mechanistic, semi-empirical, and response surface models to estimate the time of containment failure. Containment failure occurs when the container/overpack surrounding the waste form is breached along with the failure of the cladding, if modeling spent fuel. Figure 4.1 shows the overall structure of the corrosion modeling.

\subsubsection{Container/Overpack}

Mathematical models are required for the physical processes of pitting corrosion, general (uniform) corrosion, stress corrosion cracking (transgranular and intergranular), intergranular attack, and galvanic corrosion. However, it should be noted that some of these models may be eliminated in the future, depending on the material(s) chosen for the waste containers. For example, a single-material container would not be expected to be susceptible to intergranular attack, but a coated material may be susceptible to crevice effects. In the first iteration, it is suggested that the rnodel requirements be based on the assumption that the chosen material could be susceptible to the following:

- Pitting - depending on future (unknown) changes in repository chemistry

- General (uniform) corrosion - to account for oxidizing conditions and also liquid conditions

- Stress corrosion - because pits, for example, may evolve into cracks which could be exacerbated by mechanical loads

- Intergranular attack - depending on the container material. 


\section{Waste Package Containment Process}

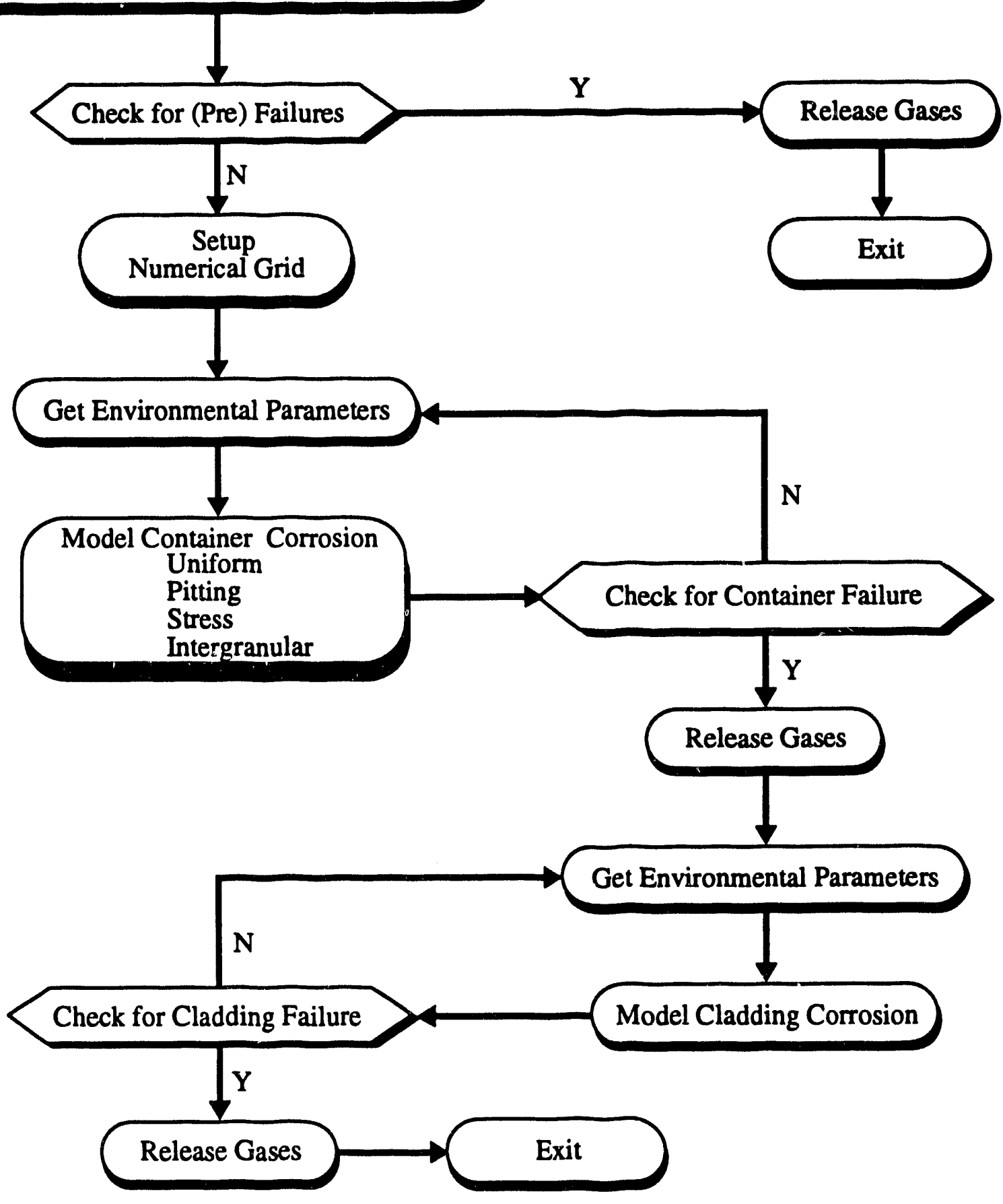

Figure 4.1. Overall Structure of the Waste Package (WP) Containment Process 


\subsubsection{Operational Features}

The AREST code will contain the capability to model output uncertainties of the corrosion process and sensitivities of the output of the conceptual models separate from modeling release and transport. The models should be mathematically straightforward so that they can be inverted for use in possibly iterative solutions that may be required for interactions between other modules of the AREST code. For example, interaction between mechanical, thermal, transport, and radiolytic modules of the AREST code are expected.

Each model should calculate the required output in an incremental manner. Account should be taken of the change in the corrosion rate as a function of the elapsed time that the particular corrosion model has been "active", so that increments in corrosion penetration are not over-estimated. The term "active" is important in relation to observations that many corrosion mechanisms can become temporarily inactive depending on changes in chemistry or passive film formation.

Each corrosion model should be "generic" enough in mathematical form so that a range of other materials could be modeled by changing the model parameters. This is consistent with the requirement that the models be mathematically straightforward and invertible. Semi-empirical models are expected to satisfy this requirement. Some examples specific to the pitting corrosion model have been discussed elsewhere (Henshall 1992; Hashimoto et al. 1992)

Each model should be capable of modeling a two-dimensional container surface area of known extent. This capability is for adaptability to the AREST code numerical mesh size, which may vary from problem to problem. It is also needed to permit evaluation of the possibility of local cells occurring during the evolution of a particular simulation. Local cells may be created or destroyed as the time-dependent boundary conditions evolve, or during simulations of the effects of major geologic motions or human intrusions.

Each model should contain provisions for enhancement effects, such as accelerated corrosion caused by radiolysis or biological factors, should these be found important in future work. This capability will allow for complexity in the models.

\subsubsection{Model Parameter Uncertainties}

It must be recognized that the desired databases for detailed model development currently do not exist. However, it is still necessary to evaluate the means and standard deviations for each of the corrosion model parameters. Consequently, whatever data that is available must be used for the model development. Mean values must be estimated for physically relevant materials and chemistries. This will seriously limit the amount of available data and cause standard deviations that will most likely be very large. Thus, we will estimate the models and the standard deviations using a larger database consisting of "similar" materials and chemistries. Based on expert judgement, documented thoroughly and carefully, other relevant data will be added to our database for developing models and estimating standard deviations. 


\subsubsection{Model Outputs}

The container will be discritized into separate nodes, with each node being modeled for corrosion until it is considered failed. Failure conditions for each mode of corrosion will be checked for each node. Failure conditions will be established by the user, with failure time and mode being output for each node. Also, each corrosion model that is active during a time step shall output the maximum and average depth of penetration through the container wall, the incremental and accumulated amount of material removed from the container wall, and the chemical and physical state of the corrosion product(s), e.g., $\mathrm{Cr}_{2} \mathrm{O}_{3}$ solid film adhering to the wall, or $\mathrm{Fe}_{2} \mathrm{O}_{3}$ dissolved in water.

\subsubsection{Special Considerations}

Because the upgraded AREST code will accommodate time and temperature dependent boundary conditions, it is quite possible that different corrosion models will activate and/or deactivate at successive time steps. It is therefore recommended that some method be implemented to choose the proper corrosion model(s) for calculation during any particular time step, in advance of the actual calculations. This implies that some sort of screening is needed to select the proper corrosion model. It is suggested that this screening be implemented in the form of a potential-pH (Pourbaix) diagram, at least in the first generation. Such a screening method may be useful when interactions between major processes are activatcd and when iterative calculations must be performed. It also allows a record of corrosion model selections to be stored in a very compact digital form (binary storage using masking functions).

Each element of the container surface in the numerical grid will also be assigned a flag to indicate whether it has failed. A container element is assumed to be partially failed if a through-wall breach has occurred, and gases from inside the container have escaped. For example, a pinhole breach caused by pitting may reseal, but if gases have escaped, the container is still partially failed. Note that a pinhole at a higher vertical position on the container can potentiaily release more gas than one at a lower position. Some means of assigning a relative value to the location of a failure may be needed in the future to take advantage of local areas on the container via the grid. A container element is totally failed if it has a through-wall breach and has released material that was previously in solid form at emplacement (e.g., spent fuel or glass).

\subsubsection{Cladding}

Models for analyzing the degradation of the zircaloy cladding surrounding the spent fuel will be implemented in the new version of the AREST code. Van Luik (et al. 1987) provides a collection of information that can be used to determine the ability of the cladding to contribute to the containment of radionuclides. An analytical model currently exists that estimates creep-rupture failure rates in a dry storage condition (Santanam et al. 1990). This type of model and/or numerical models will be implemented into the AREST code. 


\subsection{Failure Distributions}

We will also retain and enhance the capability to model containment failure as a realization from a statistical or user-supplied distribution. This capability will be useful for both sensitivity and uncertainty analyses. It will also allow the user to control the specific time of failure. 


\subsection{Waste Package Release}

Based on currently expected behavior, release processes for the engineered barrier system can be divided into two categories based on the time required to reach sub-boiling temperatures at the surface of a waste package $\left(t_{r}\right)$. After closure of the repository until time $t_{r}$, liquid water cannot contact the waste packages except through unexpected events such as human intrusion, severe changes in the water table depth, or water infiltration rates due to climate change. Consequently, under the expected conditions, release of radionuclides in the gaseous state need only be considered over the time range $0<t<t_{r}$. However, potentially important changes in the physical and chemical properties of the waste form can occur during this time period such as oxidation of the spent fuel (Einziger et al. 1992) and vapor phase hydration of borosilicate glass (Bates et al. 1988). At times greater than $t_{r}$, liquid water can come into contact with a waste package, so aqueous dissolution of the waste form and mass transport of released radionuclides can occur. The AREST code will be capable of calculating radionuclide release rates over each of these time frames, as illustrated in Figure 5.1. The conceptual models that will be implemented to describe waste package release processes are described in the following sections.

\subsection{Nuclide Mobilization}

The current version of the AREST code contains models for nuclide mobilization that assume

- a user input constant concentration or temperature-dependent concentration for solubility-limited elements;

- a $\mathrm{UO}_{2}$ solubility function (Garisto and Garisto 1985) that is used to calculate proportional concentrations for other radionuclides based on inventory in the fuel;

- constant flux at the waste form surface (further assuming a constant reaction rate of the waste form); and

- a time-varying surface concentration at the surface of a glass waste form (based on a coupled chemical-mass transport model).

With the possible exception of the last item listed above, none of these assumptions are adequate for performance assessment calculations. The primary reason is that radionuclide solubilities and dissolution rates of the waste form are highly sensitive to the chemical and physical environment of the waste package. The first three assumptions at best account for a constant chemical environment around the waste package or do not take groundwater chemistry into account at all. The new version of the AREST code will incorporate explicit provisions to treat time-dependent chemical interactions of groundwater with the waste form. The overall structure for modeling the waste form surface concentration is shown in Figure 5.2 and discussed in the following sections. 


\section{Waste Package Release Process}

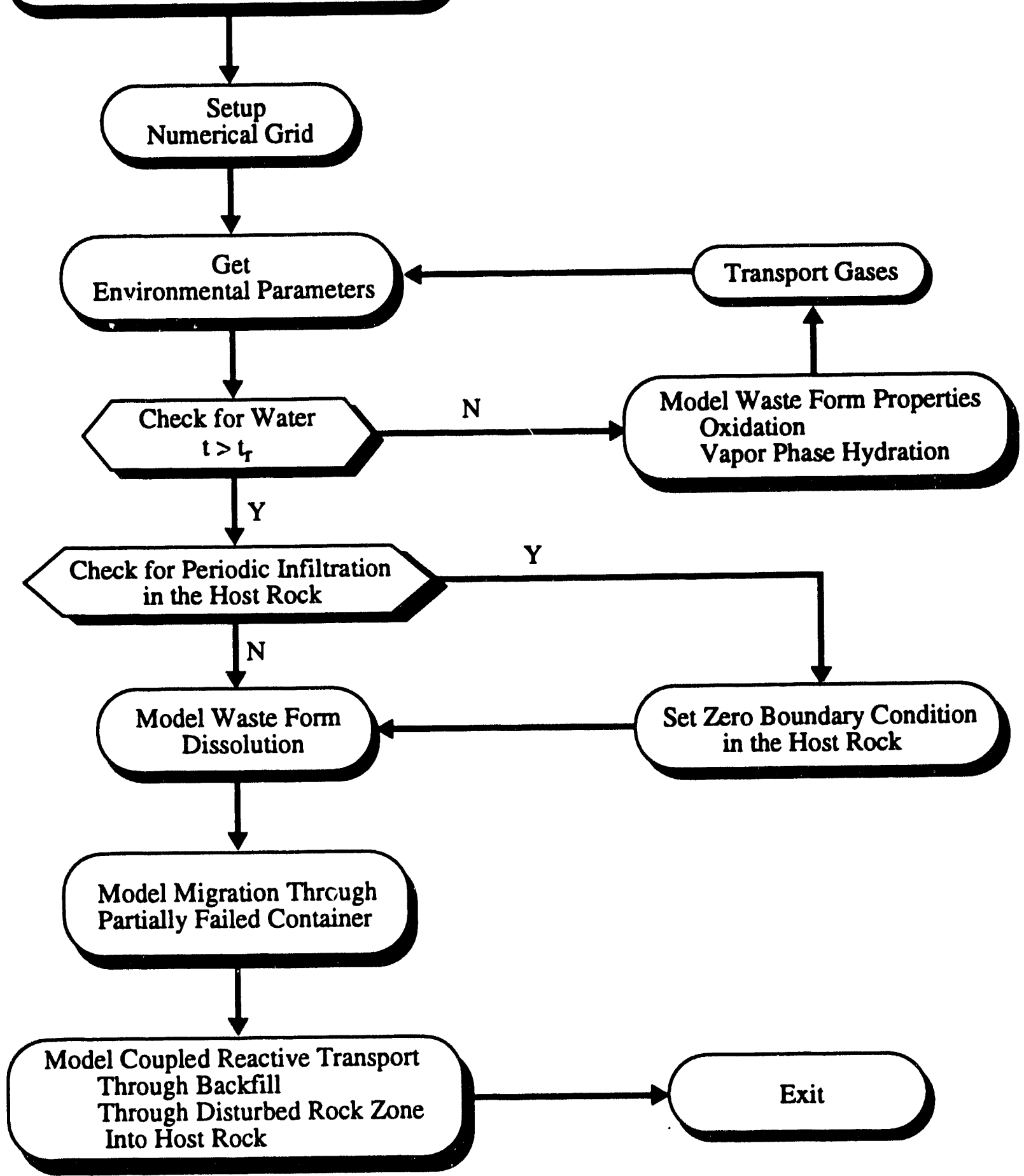

Figure 5.1. Overall Structure of the Waste Package (WP) Release Process 


\subsubsection{Matrix Dissolution}

Approximately $95 \%$ to $98 \%$ of the waste will be contained in the matrix of the waste form (Apted et al. 1989; Strachan et al. 1990). Different conceptual models for dissolution of spent fuel and borosilicate glass will be incorporated as described below.

\subsubsection{Spent Fuel}

The dissolution rate of spent fuel will be predicted based on a semi-empirical model. The model will be based on the latest experimental data available from ongoing experimental programs within the Yucca Mountain project and other projects throughout the world. The model will predict fission gas release and dissolution rates of fuel with different burnups. The dissolution model will explicitly account for changes in groundwater chemistry such as $\mathrm{O}_{2}, \mathrm{pH}$, and the concentration of important anions such as $\mathrm{HCO}_{3}^{-}$. The model will be updated as additional data is developed on the effects of other groundwater components such as $\mathrm{Si}$ and $\mathrm{Ca}$.

Before contact with liquid water, some spent fuel elements may be breached, thereby exposing the $\mathrm{UO}_{2}$ matrix to air. It has been demonstrated in laboratory experiments that spent fuel can oxidize to $\mathrm{U}_{3} \mathrm{O}_{8}$ rapidly when exposed to air at temperatures above $200^{\circ} \mathrm{C}$ (Woodley et al. 1989). One important consequence of this reaction is the volume expansion that occurs. Stresses induced along the grain boundaries tend to break the fuel into particles with much higher surface area than the intact fuel. Water contacting the particulate material is much more likely to rapidly release the entrained fission products, which are highly soluble in water under oxidizing conditions. It is not yet clear whether the intrinsic dissolution rate of $\mathrm{U}_{3} \mathrm{O}_{8}$ is significantly different from $\mathrm{UO}_{2}$ or the intermediate oxidation states such as $\mathrm{U}_{4} \mathrm{O}_{9}$. The AREST code will contain a mechanistic model to calculate the time-temperature transformation (TTT) of $\mathrm{UO}_{2}$ to the higher oxidation states. This model will be coupled with a semi-empirical model to estimate the change in fuel surface area and extent of cladding breach as a function of oxidation of the fuel. Depending on the availability of supporting experimental data, a model that accounts for changes in the intrinsic dissolution rate of spent fuel as a function of oxidation state will also be included in the AREST code.

\subsubsection{Glass}

The current version of the AREST code contains a mechanistic model that describes the dissolution kinetics and changes in groundwater chemistry that occur during the aqueous dissolution of a glass waste form. This model couples the glass dissolution process with mass transport into a backfill material. It is both computationally efficient and robust. We anticipate needing relatively minor modifications to incorporate the glass dissolution model into the numerical transport models that will be developed for the AREST code. The primary addition that will be needed is to explicitly account for the process of vapor phase hydration that will occur in those waste packages that fail before $t_{r}$. 


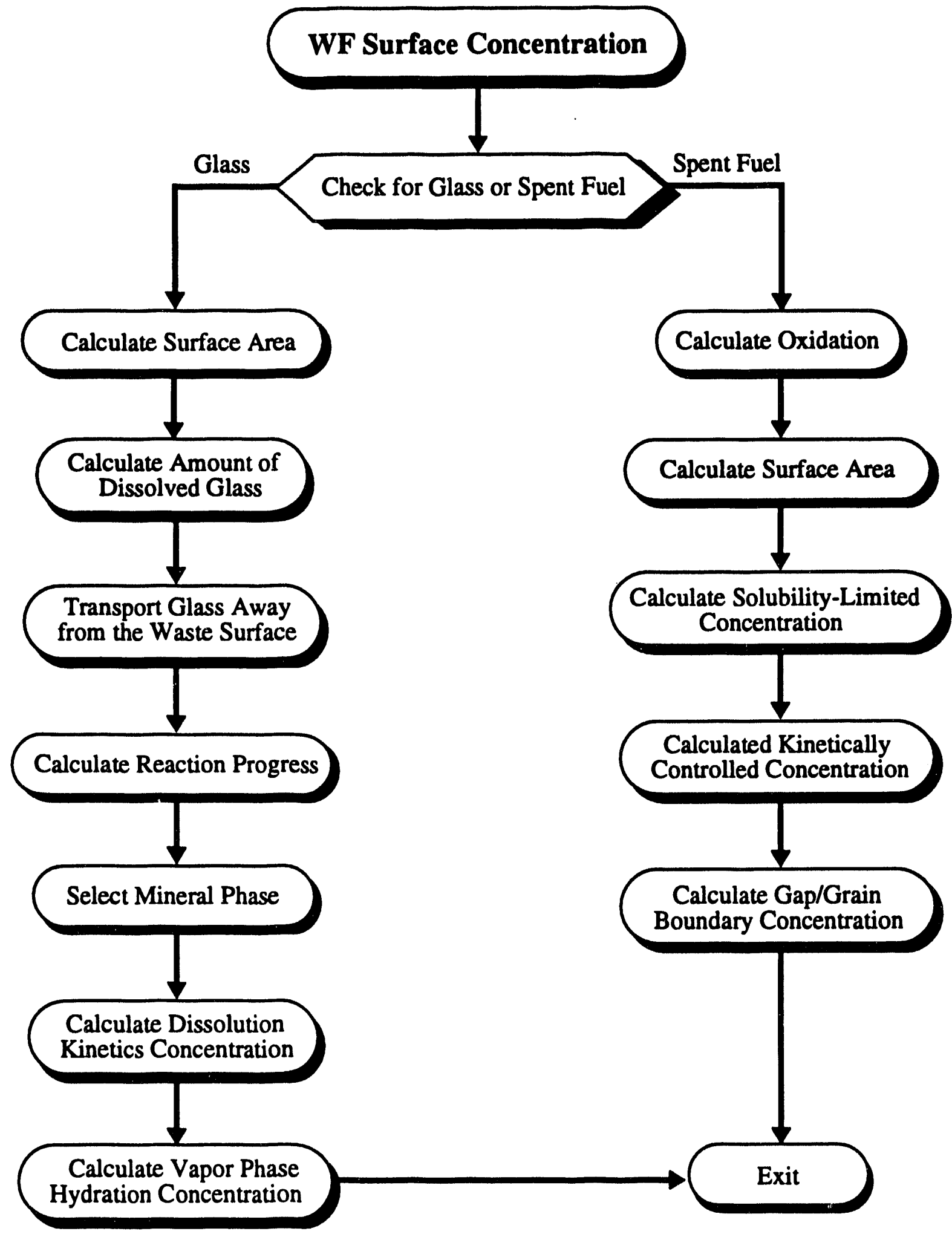

Figure 5.2. Structure of the Waste Form Surface Concentration Module 


\subsubsection{Instant Release}

For spent fuel, the fast or instant release of the soluble fission products is distributed between the fuel-cladding gap and the $\mathrm{UO}_{2}$ grain boundaries. For a glass waste form, an analogous release may occur from a porous alteration layer that develops from vapor-phase hydration (Bates et al. 1988). The modeling of the instant release is discussed in the following sections.

\subsubsection{Spent Fuel Gap/Grain Boundaries}

The release of the fission products from the gap between the cladding and the fuel and from the grain boundaries of the spent fuel will be conservatively lumped into a single source. The release of these fission products is expected to occur very rapidly if liquid water contacts the spent fuel waste form. The amount of fission products that are present in the gap and grain boundaries will be modeled by using an inventory simulated from a statistical or user supplied distribution, or by using a relationship based on fuel operation parameters, such as burnup or temperature. This relationship will be developed from data collected from spent fuel experiments. The "instant" release fraction will be additionally modified by accounting for changes in the structural integrity of the fuel, depending on the extent of oxidation as described in Section 5.1.1.1.

\subsubsection{Gaseous Release}

A model for analyzing the release and transport of gaseous ${ }^{14} \mathrm{C}$ has been developed at the University of California at Berkeley (Light et al. 1990). This model analyzes release through partially failed containers. This analytical model, or similar numerical models, will be incorporated into the AREST code to treat release of radionuclides in the gaseous state.

\subsubsection{Vapor Phase Hydration}

Work conducted at Argonne National Laboratory has indicated that for some borosilicate waste glasses, exposure to high temperature water vapor leads to the formation of a hydration rind on the glass surface. The hydration rind consists of a series of secondary mineral phases. This porous layer may be poorly adherent to the glass surface and may also provide little resistance to the movement of any liquid water that subsequently contacts the waste form. Consequently, soluble elements entrained in this layer are expected to be rapidly released once liquid water contacts the waste package. We envision the release process to be entirely analogous to the "instant" release of gap inventory fission products with spent fuel. A model will be incorporated into the AREST code that will predict the extent of vapor phase hydration as a function of temperature and relative humidity. This model will then be used to develop an "instant" release source term for those waste packages that are assumed to fail early and expose the glass to high temperature water vapor. 


\subsection{Nuclide Transport}

The AREST code will primarily model liquid transport of radionuclides. The transport of a gaseous nuclide, primarily ${ }^{14} \mathrm{C}$, will be done by assuming an instantaneous transport from the container surface to the host rock. That is, whatever is released from the waste form and can migrate through the partially failed container, can instantaneously transport through the backfill.

Numerical modeling of liquid transport is an area where the AREST code needs to be upgraded. The new version will be capable of predicting multicomponent solute transport with simultaneous chemical reaction and radioactive decay. The model will explicitly account for changes in the nearfield groundwater chemistry that occurs as a consequence of the dissolution or corrosion of the waste form and other engineered-barrier materials. This capability will be the unique feature of the AREST code compared with other reactive transport models that have been previously developed in the U.S. and other countries. The transport model will be structured to allow the free mixing of kinetic and equilibrium-controlled reactions throughout the spatial domain. If feasible, the model will also account for the changes in water chemistry that result from radiolysis.

The geometric configuration will utilize an orthogonal grid in two space dimensions to predict mass transport through a backfill and into the host rock region. The models will provide constraints on solubility limits, radionuclide decay, and decay chain ingrowth at each node and time step throughout the EBS. Spatial discretization routines will assist the user in setting up the problem so that the desired accuracy of the solution to the difference equations will be achieved. For example, a user may wish to simulate migration through four regions, including

- a partially failed container

- a backfilled region

- a rock region that has been disturbed during the tunnelling or drilling of a bore hole

- a fractured tuffaceous host rock.

The user will be able to adjust the level of detail in each region of interest based on the selection of the grid and grid spacing.

At the potential site for the repository at Yucca Mountain, changes in global climate far into the future may result in periods when water recharge rates are sufficiently high to cause matrix, fracture, or combined matrix-fracture flow (Buscheck et al. 1991). Consequently, the AREST code will need to model the effects of these periodic events on radionuclide release. The user will input data on the statistical nature of the infiltration events and will predetermine the characteristics of the episodic event, including whether the flow is matrix or fracture-dominated. This data will then be used by the AREST code to wash away or flush the concentrations in the fractures and/or rock matrix for times corresponding with the duration and frequency distributions input by the user, and thus modifying the boundary at the waste package/host rock interface. 


\subsection{Colloid Transport}

Colloid transport has received considerable attention in the literature. Bates et al. (1990) have found actinide colloids in their wet-drip release experiments with several waste glasses. These results are consistent with other evidence in the literature for colloid formation in closed-system tests reacting glass with water (Oloffson et al. 1982; McVay and Buckwalter 1982; Avogadro and de Marsily 1984; Shade et al. 1984; McGrail 1986). However, the formation or potential for formation of colloids in the near-field is not at issue. What is considerably less clear is the potential for transport out of the EBS of any colloids that do form.

Diffusive transport of colloid size particles is physically impossible in partially saturated tuff, where diffusion occurs across thin water films on the mineral surfaces. Consequently, episodic infiltration events where convective flow is induced for periods of time is the only probable means of transporting colloids. With a properly designed engineered-barrier surrounding the waste package, diffusive transport will be the only means of radionuclide release to the host rock. Consequently, from the point of view of the EBS with which the AREST code is concerned, episodic infiltration events need only change the boundary conditions that are applied for the solute transport problem. There is no need for implementation of a highly complex colloid transport model requiring data on colloid size, growth rates, electrophoretic mobility, etc., that has little hope of being determined quantitatively or predicted even qualitatively. Because of these factors and the lack of a defensible colloid transport model, we are not considering radionuclide release associated with colloids in developing the requirements for the new version of the AREST code. 


\subsection{Uncertainties}

An accurate description of a PA code, which represents a physical model, is that the code has inputs consisting of a set of parameters-call the set $\theta$-which typically describes physical and design features. The outputs from a PA code typically are measures of performance and quantities of regulatory interest. Uncertainties about the model that the code embodies are represented, albeit incompletely, by a distribution on the parameter set-call the distribution $\Pi$. An uncertainty analysis is a study of the distribution of $f(\theta)$ induced by $\Pi$, where $f(\theta)$ is the function being estimated by the PA code.

\subsection{Source of Uncertainties}

Sources of uncertainties for a PA code include physical surroundings, design parameters, and empirical relations. The physical surroundings are the environmental processes that describe the nearfield and the waste package. These uncertainties would arise from modeling parameters using process-specific support codes, using site-specific data measured in field studies, and ignoring certain processes that actually may have an effect on the performance.

The design parameters include properties of the backfill and host rock (e.g., porosity and tortuosity), the waste form characteristics (e.g., waste loading and storage time duration), the waste container properties (e.g., material), and dimensions (e.g., container thickness and backfill thickness). Uncertainties will arise in measuring these values and manufacturing the system to specifications.

Uncertainties with empirical relationships occur with obtaining experimental data and developing equations from the experimental data.

\subsection{Uncertainty Analysis Options}

The usual methods of uncertainty analysis are various Monte Carlo (MC) simulation methods. This section describes the usual variants of MC used for an uncertainty analysis and also describes a variance propagation strategy for uncertainty analysis (Owen 1992a). These methods or similar types of methods will be implemented into the new version of the AREST code.

The authors realize that the complexity and computational demands of the transport module will limit the extent of uncertainty analysis to simplified problems. This section describes several techniques for estimating uncertainties with the actual techniques that will be implemented being based on the complexity of the models developed and documented in the mathematics document. We realize that this section is much more technical than the other sections throughout this document. 


\subsubsection{Notation}

The following is the main notation that is used throughout this section:

$\theta \quad$ is the set of input parameters

$\Pi$ is the distribution on the input parameters, $\theta$

$f$ is the model being estimated by the PA code

$\varepsilon$ is the expectation operator; e.g., $\varepsilon[\theta]=\int_{\theta} \Pi(\theta) d \theta$

$\nu$ is the covariance operator; e.g., $\nu[\theta]=\varepsilon\left[\left(\theta-\mu_{\theta}\right)\left(\theta-\mu_{\theta}\right)^{t}\right]$

$\mu_{\theta}$ is the mean of the input parameters, $\mu_{\theta}=\varepsilon[\theta]$

$\Sigma_{\theta}$ is the covariance of the input parameters, $\Sigma_{\theta}=\nu[\theta]$.

\subsubsection{Monte Carlo Methods}

The first method discussed in this section is the ordinary MC method. This method is used to examine the distributions of the model, $f(\theta)$, by randomly sampling values for the input data set, $\theta_{\mathrm{i}}$, from the input distribution, $\Pi$. Thus, this method calculates the values $f\left(\theta_{1}\right)$ and forms various empirical ciistributions based on these values. The advantages of this method are that 1 ) it is conceptually straightforward and 2) it provides a natural way to study the induced distribution. However, ordinary MC methods can consume a lot of computer time, particularly if the tails of the induced distribution are needed.

Another form of MC simulation is the stratified Monte Carlo. With this method, the input data set is randomly selected based on a design strata of the input distribution. This method is better than or equal to the ordinary MC method when estimating the expected value, $\varepsilon[f(\theta)]$. The advantages of this method are that 1) it is conceptually straightforward, 2) it produces a smaller variance than the ordinary MC method, and 3) the formulas for the various properties of the induced distributions are readily available. However, the performance of this method is based on the choice of the strata.

Finall;, there is the Latin Hypercube Sampling (LHS) method. It is another form of MC simulation which is better than or equal to the ordinary MC method when estimating the expected value, $\varepsilon[f(\theta)]$. In practice, LHS advantages are 1) it can outperform stratified MC methods of estimating the expected value, 2) it generally produces smaller variances, and 3) algorithms currently exist which provide methodology to impose rank correlation structures on the inputs. While estimates of the sampling error of the mean are available for LHS, estimates of the variance of the model, $\nu[f(\theta)]$, are not quantifiable (Owen 1992b).

\subsubsection{Propagating Variances}

Using a propagation of variance method, we assume that the uncertainties in the model parameters are satisfactorily captured by the covariance of the input parameters, $\Sigma_{\theta}$. This covariance is propagated to $f(\theta)$ using an approximation presented by Rao [1973, theorem 6.a.2 (ii)], by expanding $f(\theta)$ in a Taylor series about $\mu_{\theta}$ and using the first two terms in the series as an approximation to $f$. The general series is: 


$$
f(\theta)=f\left(\mu_{\theta}+\left(\theta-\mu_{\theta}\right)\right)=\sum_{k=0}^{m} \frac{1}{k !} \sum\left(D_{i_{1}} \cdots i_{k} f\right)\left(\mu_{\theta}\right)\left(\theta-\mu_{\theta}\right)_{i} \cdots\left(\theta-\mu_{\theta}\right)_{i_{k}}+r\left(\theta-\mu_{\theta}\right)
$$

where $r\left(\theta-\mu_{\theta}\right)$ converges to zero faster than $\left|\theta-\mu_{0}\right|$, as $\theta \rightarrow \mu_{0}$. By cutting off the expansion in this equation at $m=1$, we have the approximation for $\nu[f(\theta)]$ :

$$
v[f(\theta)]=\left(D_{1} f\left(\mu_{\theta}\right), \ldots, D_{N} f\left(\mu_{\theta}\right)\right)^{r} v[\theta]\left(D_{1} f\left(\mu_{\theta}\right), \ldots, D, f\left(\mu_{\theta}\right)\right)
$$

The strategy described in the preceding paragraphs can be modified in a number of ways. One modification is to consider other expansions and search for convenient variance formulas for those expansions. An expansion currently being studied in the statistics literature is the following:

$$
f(\theta)=\sum_{i} f_{i}\left(\theta_{i}\right)+\sum_{i=j} f_{i}\left(\theta_{p} \theta_{j}\right)+\ldots
$$

The first term represents $f$ as an "additive" function. The next and higher order sums correspond to increasingly higher order interactions.

\subsection{Code Requirements for Uncertainty Analyses}

For a Monte Carlo approach, uncertainty analysis can be implemented as a "wrapper" to be placed around a code which calculates $f(\theta)$. The code will be exercised with repeated sampling of input parameters. This requires hundreds, even thousands, of runs. Thus, the models need to be very efficient and typically simplified, analytical or response surfaces, in order to make the repeated runs.

The variance propagation approach requires that derivatives of the models be calculated and evaluated. Currently, the models are not developed, thus to evaluate for appropriateness of this technique can not be done. Once the models are developed, this technique will be evaluated for possible implementation into the AREST code. 


\subsection{Computer Requirements}

This section describes the specific computer related requirements for the new version of the AREST code. These requirements are broken into three sections which describe the computer requirements, performance requirements, and specific attributes of the code and the user of the code.

\subsection{Host Computer}

The current version of the AREST code runs on a UNIX SparcStation. ${ }^{(a)}$ The computational part of the AREST code is written in FORTRAN, while the Input Manager and the Plot Manager arc written in C. The XVIEW ${ }^{(a)}$ toolkit, of the OpenWindows ${ }^{(a)}$ graphical X-windows environment, was used to develop the dynamic user-interface for the Input Manager and for the Plot Manager. The Plot Manager uses the Uniras ${ }^{(b)}$ graphics libraries to create the graphical representation of the results.

The new version of the AREST code will again be developed for the UNIX SparcStation. Developing a system on a specific platform allows for the utilization of more of the capabilities of the software, hardware, and software-hardware interactions. This philosophy allows for the most capabilities being incorporated into the system as compared to restricting enhancements due to the development of a system that will run on several different types of hardware and software. The computational part of the AREST code will, however, be portable to other platforms running a similar FORTRAN compiler. The FORTRAN compiler used for the AREST code is FORTRAN 77 with Vax/VMS extensions, version 1.4 on the SparcStation.

The current version of the AREST code uses approximately 5 Mbytes of memory and 100 Mbytes of disk space. This includes the user interface and the computational model. The new version will use approximately twice the memory (10 Mbytes) and possibly 1.5 to 2 times the disk space (200Mbytes) as compared to the current version.

\subsection{Performance}

The current version of the AREST code is very efficient. Runs for a typical analysis (e.g., single waste package, 5 nuclides) may take 2 CPU seconds for the analytical transport models or up to 2 CPU minutes using the glass dissolution model and the one-dimensional transport model.

Since the AREST code will be used for analyses with different levels of detail-from very detailed when analyzing the conceptual-level and process-level models to moderately detailed when analyzing the waste package domain model--computer performance will still be an issue. As described in previous sections, the AREST code will be used to analyze model and data sensitivities and performance model uncertainties. Thus, the AREST code will be used to make a limited number

(a) Registered trademark of Sun Microsystems, Inc.

(b) Registered trademark of Uniras, Inc. 
of repeated runs/analyses. The current, probabilistic, version of the AREST code typically analyzes 100 to $\mathbf{5 0 0 0}$ waste packages for a single analysis. This number of simulations is not realistic with the more detailed numerical version of the AREST code, where a typical analysis may use 10 to 50 simulated waste packages. Thus, an analysis of a single waste package that takes one to five hours of CPU time is not unrealistic, especially since each waste package could be simulated separately on different computers/CPUs.

\subsection{Attributes}

The current version of the AREST code is maintained under a configuration management (CM) tool called SCCS(a) on the UNIX SparcStation. All modifications to the code are and will be documented using this $\mathrm{CM}$ tool. Documentation will also be placed under the same $\mathrm{CM}$ tool. The AREST code and the output for each analysis will be labelled, such that the version, the configuration management number, and the relevant dates are marked.

Finally, the code is being designed so that the user of the system has to be cognizant of the following:

- UNIX and the SparcStation

- the waste package and EBS system

- a set of documentation that will be developed for the new version of the AREST code, including

1. Software requirements specification

2. Software development plan

3. Mathematics document

4. Software design document

5. Software user guide.

(a) Registered trademark of Sun Microsystems, Inc. 


\subsection{User Interface}

The current version of the AREST code contains a graphical user interface for both input to the model and viewing the results (Nakamura and Wilkins 1992). Interactive input to the AREST code is done through the Input Manager, while interactive plotting is done using the Plot Manager. Both the Input Manager and the Plot Manager are described in the next two sections.

A help utility and a cross-reference utility are provided with the AREST code. The help utility is a narrative description of the individual parts of the user interface. The reference utility provides easily accessible on-line help and cross-reference for a variety of related topics and variables.

\subsection{Input Manager}

The current version of the Input Manager allows the user to input all parameters as a single discrete value, multiple discrete values for sensitivity analysis, or as a simulated value from a statistical distribution. The user can select from two types of sensitivity analysis designs: full factorial or base-alternate; and from several statistical distributions-uniform, normal, exponential, triangular, or from a user-supplied probability density curve. Using the Input Manager, input parameters can be correlated with other input parameters using simple relationships. The Input Manager outputs a data file which is read directly into the computational part of the AREST code.

In the new version of the AREST code, the Input Manager will be expanded to allow for input of new data for the numerical models (e.g., defining the grid and boundary conditions for the new numerical transport models); and will include more designs for sensitivity analysis (e.g., Latin Hypercube Sampling), more statistical distributions (e.g., Weibull and log distributions), and more correlation structure of the input parameters. Provisions for doing sensitivity analyses of the individual conceptual-levei models and process-level models will also be added.

\subsection{Plot Manager}

The current version of the Plot Manager allows the user to interactively plot the calculated results from the AREST code. The user has a great deal of flexibility in plotting the results. The specific types of plots include:

- release rates or concentrations as a function of time

- release distributions of simulated waste packages as a function of time

- probability density function of release from simulated waste packages at a specified time

- probability density function of a simulated input parameter

- two-dimensional scatter plot of simulated input parameters

- release contour plots at a specified time as a function of two simulated input parameters

- radionuclide concentrations as a function of time and one-dimensional distance from the waste container. 
In the current version, the user has the capability to combine different simulated runs/scenarios onto a single plot. The user can also control the output device and the composition of the graphics, including:

- specifying that the output be displayed on the screen or written to a PostScript file

- specifying titles, footnotes, and axis labeling and scaling

- specifying units for release rates and concentrations: curies, becquerels, grams, moles, or parts

- specifying the time frame of the plot: time since container failure or time since repository closure

- controlling plot specification: individual waste package release rate, average waste package release, or cumulative release

- having the option to save and reuse the plot description.

Enhancements to the Plot Manager will include:

- three-dimensional plots: release as a function of two simulated input variables or release as a function of a two-dimensional design (spatial)

- plots of input and calculated intermediate data: time-temperature histories, groundwater compositions, reaction progress, or dissolution rates

- release profiles showing propagation of fronts and precipitation through the backfill and rock regions. 


\subsection{References}

Apted, M. J., A. M. Liebetrau, and D. W. Engel. 1989. The Analytical Repository Source-Term (AREST) Model: Analysis of Spent Fuel as a Nuclear Waste Form. PNL-6347, Pacific Northwest Laboratory, Richland, Washington.

Arthur, R. C., and W. M. Murphy. 1989. "Gas-Water-Rock Interaction During Isothermal Boiling in Partially Saturated Tuff at $100^{\circ} \mathrm{C} \& 0.1 \mathrm{MPa}$." PNL-SA-15538, Pacific Northwest Laboratory, Richland, Washington.

Avogadro, A., and G. de Marsily. 1984. "The Role of Colloids in Nuclear Waste Disposal." In Scientific Basis for Nuclear Waste Management VII, ed. G. L. McVay, Materials Research Society, Pittsburgh, Pennsylvania.

Bates, J. K., T. Abrajano, W. L. Ebert, J. J. Mazer, and T. J. Gerding. 1988. "Experimental Hydration Studies of Natural and Synthetic Glasses." In Materials Research Society Symposium Proceedings, vol. 123, ed. E. V. Sayre, pp. 237-244. Materials Research Society, Pittsburgh, Pennsylvania.

Bates, J. K., W. L. Ebert, and T. J. Gerding. 1990. "Vapor Hydration and Subsequent Leaching of Transuranic-Containing SRL and WV Glass." In Proceedings of the International Topical Meeting on High-Level Radioactive Waste Management, Las Vegas, Nevada.

Buscheck, T. A., J. J. Nitao, and D. A. Chesnut. 1991. "The Impact of Episodic Nonequilibrium Fracture-Matrix Flow on Geological Repository Performance." In Proceedings of the Topical Meeting on Nuclear Waste Packaging-FOCUS '91, Las Vegas, Nevada.

Chambré, P. L., T. H. Pigford, W. W.-L. Lee, J. Ahn, S. Kajiwara, C. L. Kim, H. Kimura, H. Lung, W. J. Williams, and S. J. Zavoshy. 1985. Mass Transfer and Transport in a Geologic Environment. LBL-19430, Lawrence Berkeley Laboratory, Berkeley, California.

Conca, J. L., and J. V. Wright. 1992. "A New Technology for Direct Measurements of Unsaturated Transport." In Proceedings of the Spectrum ' 92 International Topical Meeting on Nuclear Waste Management, Boise, Idaho.

Einziger, R. E., L. E. Thomas, H. C. Buchanan, and R. B. Stout. 1992. "Oxidation of Spent Fuel in Air at 175 to $195^{\circ} \mathrm{C}$." J. Nuclear Materials 190:53-60.

Engel, D. W., and B. P. McGrail. 1993. AREST Model Description. PNL-8659, Pacific Northwest Laboratory, Richland, Washington.

EPA (U.S. Environmental Protection Agency). 1985. 40 CFR 191, "Environmental Radiation Protection Standards for Management and Disposal of Spent Nuclear Fuel, High-Level and Transuranic Radioactive Waste." U.S. Code of Federal Regulations. 
Garisto, F., and N. C. Garisto. 1985. "A UO 2 Solubility Function for the Assessment of Used Nuclear Fuel Disposal." Nuclear Science Engineering 90:103-110.

Grindrod, P., M. Williams, M. Impey, and H. Grogan. 1991. STRENG: A Source-Term Model for Vitrified High-Level Waste. Technical Report NTB 90-48, NAGRA, Wettingen, Switzerland.

Hashimoto, M., S. Miyajima, and T. Murata. 1992. "A Stochastic Analysis of Potential Fluctuation During Passive Film Breakdown and Repair on Iron." Corr. Sci. 33:885-904.

Henshall, G. A. 1992. "Modelling Pitting Corrosion Damage of High-Level Radioactive-waste Containers Using a Stochastic Approach." J. Nucl. Mater. 195:109-125.

Kossik, R., I. Miller, and M. Cunnane. 1992. "Integrated Performance Assessment Model for Waste Package Behavior and Radionuclide Release." In Proceedings of the International High-Level Radioactive Waste Management Conference, Las Vegas, Nevada.

Liebetrau, A. M., M. J. Apted, D. W. Engel, M. K. Altenhofen, D. M. Strachan, C. R. Reid, C. F. Windisch, R. L. Erickson, and K. I. Johnson. 1987. The Analytical Repository Source-Term (AREST) Model: Description and Document. PNL-6346, Pacific Northwest Laboratory, Richland, Washington.

Light, W. B., E. D. Zwahlen, T. H. Pigford, P. L Chambré, and W. W.-L. Lee. 1990. C-14 Release and Transport from a Nuclear Waste Repository in an Unsaturated Medium. LBL-28923, Lawrence Berkeley Laboratory, University of California, Berkeley, California.

McGrail, B. P. 1986. "Radiocolloid Formation in Waste Package Leach Tests with Savannah River Defense Waste Glass in Salt Brines." In Advances in Ceramics - Volume 20: Nuclear Waste Management II, eds. D. E. Clark, W. B. White, and A. J. Machiels, American Ceramic Society, Inc., Westerville, Ohio.

McGrail, B. P., and D. W. Engel. 1992. "Coupled Process Modeling and Waste Package Performance." In Scientific Basis for Nuclear Waste Management XV, Materials Research Society, Pittsburgh, Pennsylvania.

McVay, G. L., and C. Q. Buckwalter. 1982. "The Effect of Iron on Waste Glass Leaching." PNL-SA-10474, Pacific Northwest Laboratory, Richland, Washington.

Nakamura, G. C., and M. L. Wilkins. 1992. "AREST-PNC User's Guide." In Performance Assessment Center for Engineered Barriers (PACE) Program FY 1991 Summary Report, PNC PA0865 92-001, prepared by Battelle, Pacific Northwest Laboratories for PNC, Tokoyo, Japan.

NRC (U.S. Nuclear Regulatory Commission). 1983. 10 CFR 60, "Disposal of Nuclear Radioactive Waste in Geologic Repositories." U.S. Code of Federal Regulations. 
Oloffson, U., B. Allard, B. Torstenfelt, and K. Anderson. 1982. "Properties and Mobilities of Actinide Colloids in Geologic Systems." In Scientific Basis Nuclear Waste Management V, ed. W. Lutze, Materials Research Society, Pittsburgh, Pennsylvania.

Owen, A. B. 1992a. Lattice Sampling Revisited: Monte Carlo Variance of Means Over Randomized Orthogonal Arrays. SRC Technical Report preprint C 92455, Semiconductor Research Corporation, Research Triangle, North Carolina.

Owen, A. B. 1992b. "A Central Limit Theorem for Latin Hypercube Sampling." Journal of the Royal Statistical Society, Series B, 54(2):541-551.

Pescatore, C., and T. Sullivan. 1985. "Sorption-Capacity Limited Retardation of Radionuclide Transport in Water-Saturated Packing Materials." In Scientific Basis for Nuclear Waste Management VIII, eds. C. M. Jantzen, J. A. Stone, and R. C. Ewing, Material Research Society, Pittsburgh, Pennsylvania.

Rao, C. R. 1973. Linear Statistical Inference and Its Application. Second Edition, John Wiley and Sons, New York.

Reardon, E. J. 1981. "K's - Can They Be Used to Describe Reversible Ion Sorption Reaction in Contaminant Migration?" Ground Water 19:279-286.

Santanam, L., S. Raghaven, and B. A. Chin. 1990. Zircaloy Cladding Degradation Under Repository Conditions. UCRL-100212, Lawrence Livermore National Laboratory, Livermore, California.

Serne, R. J., and A. B. Muller. 1987. "A Perspective on Adsorption of Radionuclides Onto Geologic Media." In The Geological Disposal of High Level Radioactive Wastes, ed. D. G. Brookins, Theophrastus Publications, Athens, Greece.

Shade, J. W., L. L. Ames, and J. E. McGarrah. 1984. "Actinide and Technetium Sorption on IronSillicate and Dispersed Clay Colloids." In Geochemical Behavior of Disposed Radioactive Waste, American Chemical Society Symposium Series.

Strachan, D. M., B. P. McGrail, M. J. Apted, D. W. Engel, and P. W. Eslinger. 1990. Preliminary Assessment of the Controlled Release of Radionuclide from Waste Packages Containing Borosilicate Waste Glass. PNL-7591, Pacific Northwest Laboratory, Richland, Washington.

Van Luik, A. E., M. J. Apted, W. J. Bailey, J. H. Haberman, J. S. Shade, R. E. Guenther, R. J. Serne, E. R. Gilbert, R. Peters, and R. E. Williford. 1987. Spent Nuclear Fuel as a Waste Form for Geologic Disposal: Assessment and Recommendations on Data and Modeling Needs. PNL-6329, Pacific Northwest Laboratory, Richland, Washington.

Van Luik, A. E., D. Stahl, and D. Harrison. 1992. "Progress in Waste Package and Engineered Barrier Systems Performance Assessment and Design." In Scientific Basis for Nuclear Waste Management XV, Materials Research Society, Pittsburgh, Pennsylvania. 
Woodley, R. E., R. E. Einziger, and H. C. Buchanan. 1989. "Measurement of the Oxidation of Spent Fuel Between 140 and $225^{\circ} \mathrm{C}$." J. Nuclear Technology 85.

Wang, J.S.Y., D. C. Mangold, R. K. Spencer, and C. F. Tsang. 1983. Thermal Impact of Waste Emplacement and Surface Cooling Associated with Geologic Disposal of Nuclear Waste.

NUREG/CR-2910, LBL-13341, Lawrence Berkeley Laboratory, University of California, Berkeley, California. 


\section{Distribution}

No. of

Copies

\section{OFFSITE}

C. R. Allen

Nuclear Waste Technical Review Board 1000 E. California Boulevard

Pasadena, CA 91106

A. Anderson

Argonne National Laboratory

Building 362

9700 S. Cass Avenue

Argonne, IL 60439

E. Anderson

Mountain West Research-

Southwest, Inc.

2901 N. Central Ave., \#1000

Phoenix, AZ 85012-2730

R. Andrews

INTERA

2650 Park Tower Drive

Suite 800

Vienna, VA 22180

D. H. Appel

Hydrologic Investigations

Program, MS 421

U.S. Geological Survey

P.O. Box 25046

Denver, CO 80225

M. J. Apted

INTERA Sciences

3609 South Wadsworth Blvd.

5th Floor

Denver, CO 80235
No. of

Copies

L. H. Barrett (RW-1)

Acting Director

Office of Civilian Radioactive Waste

Management

U.S. Department of Energy

1000 Independence Avenue, S.W.

Washington, DC 20585

M. L. Baughman

35 Clark Road

Fiskdale, MA 01518

D. A. Bechtel, Coordinator

Nuclear Waste Division

Clark County Department of

Comprehensive Planning

301 E. Clark Ave., Suite 570

Las Vegas, NV 89101

D. A. Beck

Water Resources Division

U.S. Geological Survey

6770 S. Paradise Road

Las Vegas, NV 89119

C. G. Bell, Jr.

Professor of Civil Engineering

Civil and Mechanical

Engineering Department

University of Nevada, Las Vegas

4504 S. Maryland Parkway

Las Vegas, NV 89154

A. Benson (RW-5)

Office of External Relations

Office of Civilian Radioactive

Waste Management

U.S. Department of Energy

1000 Independence Avenue, S.W.

Washington, DC 20585

Distr.1 
No. of Copies

E. P. Binnall

Field Systems Group Leader

Building 50B/4235

Lawrence Berkeley Laboratory

Berkeley, CA 94720

J. A. Blink

Deputy Project Leader

Lawrence Livermore National

Laboratory

101 Convention Center Drive

Suite 820, MS 527

Las Vegas, NV 89109

S. Bradhurst

P.O. Box 1510

Reno, NV 89505

L. W. Bradshaw

Program Manager

Nye County Nuclear Waste

Repository Program

P.O. Box 1767

Tonopah, NV 89049

J. C. Bresee (RW-10)

Office of Civilian Radioactive

Waste Management

U.S. Department of Energy

1000 Independence Avenue, S.W.

Washington, DC 20585

G. D. Brewer

Nuclear Waste Technical Review Board

The Dana Building, Room 3516

University of Michigan

Ann Arbor, MI 48109-1115
No. of

Copies

S. J. Brocoum (RW-22)

Analysis and Verification Division

Office of Civilian Radioactive

Waste Management

U.S. Department of Energy

1000 Independence Avenue, S.W.

Washington, DC 20585

R. L. Bullock

Technical Project Officer for YMP

Raytheon Services Nevada

Suite P-250, MS 403

101 Convention Center Drive

Las Vegas, NV 89109

D. Campbell

Technical Project Officer for YMP

U.S. Bureau of Reclamation

Code D-3790

P.O. Box 25007

Denver, CO 80225

4 J. A. Canepa

Technical Project Officer YMP

N-5, MS J521

Los Alamos National Laboratory

P.O. Box 1663

Los Alamos, NM 87545

J. E. Cantlon, Chairman

Nuclear Waste Technical Review Board 2795 Bramble Drive

East Lansing, MI 48823

Center for Nuclear Waste Regulatory

Analyses

6220 Culebra Road

Drawer 28510

San Antonio, TX 78284

Distr. 2 
No. of Copies
No. of Copies

P. A. Domenico

Nuclear Waste Technical Review Board

Geology Department

Texas A \& M University

College Station, TX 77843

2 M. J. Dorsey, Librarian

YMP Research and Study Center

Reynolds Electrical and

Engineering Co., Inc.

MS 407

P.O. Box 98521

Las Vegas, NV 89193-8521

G. L. Ducret, Associate Chief

Yucca Mountain Project Division

U.S. Geological Survey

P.O. Box 25046

421 Federal Center

Denver, CO 80225

Economic Development Department

City of Las Vegas

400 E. Stewart Avenue

Las Vegas, NV 89101

N. Z. Elkins

Deputy Technical Project Officer

Los Alamos National Laboratory

MS 527

101 Convention Center Drive, Suite 820

Las Vegas, NV 89101

D. R. Elle, Director

Environmental Protection Division

U.S. DOE Nevada Operations Office

P.O. Box 98518

Las Vegas, NV 89193-8518 
No. of

Copies

Eureka County Board of Commissioners

Yucca Mountain Information Office

P.O. Box 714

Eureka, NV 89316

C. E. Ezra

YMP Support Office Manager

EG\&G Energy Measurements, Inc.

MS V-02

P.O. Box 1912

Las Vegas, NV 89125

P. K. Fitzsimmons, Technical Advisor Office of Assistant Manager for

Environmental Safety and Health

U.S. DOE Nevada Operations Office

P.O. Box 98518

Las Vegas, NV 89193-8518

A. L. Flint

U.S. Geological Survey

MS 721

P.O. Box 327

Mercury, NV 89023

J. Fordham

Water Resources Center

Desert Research Institute

P.O. Box 60220

Reno, NV 89506

J. Foremaster

City of Caliente Nuclear Waste

Project Office

P.O. Box 158

Caliente, NV 89008
No. of

Copies

2 L. D. Foust

Nevada Site Manager

TRW Environmental Safety Systems

101 Convention Center Drive

Suite 540, MS 423

Las Vegas, NV 89109

D. L. Fraser

Reynolds Electrical and

Engineering Co., Inc.

MS 555

P.O. Box 98521

Las Vegas, NV 89193-8521

5 C. P. Gertz, Project Manager

Yucca Mountain Site Characterization

Project Office

U.S. Department of Energy

P.O. Box 98608, MS 523

Las Vegas, NV 89193-8608

P. A. Glancy

U.S. Geological Survey

Federal Building, Room 224

Carson City, NV 89701

T. Hay, Executive Assistant

Office of the Governor

State of Nevada

Capitol Complex

Carson City, NV 89710

L. R. Hayes

Technical Project Officer

Yucca Mountain Project Branch-MS 425

U.S. Geological Survey

P.O. Box 25046

Denver, CO 80225

Distr.4 
No. of

Copies

D. Hedges

Quality Assurance

Roy F. Weston, Inc.

4425 Spring Mountain Road,

Suite 300

Las Vegas, NV 89102

E. J. Helley

Branch of Western Regional

Geology, MS 427

U.S. Geological Survey

345 Middlefield Road

Menlo Park, CA 94025

J. D. Hoffman

Nuclear Waste Repository

Oversight Program

Esmeralda County

P.O. Box 490

Goldfield, NV 89013

4 INTERA, Inc.

101 Convention Center Drive

Phase II, Suite 540

Las Vegas, NV 89193

ATTN: R. W. Nelson

A. E. Van Luik

H. N. Kalia

E. B. Mann

C. H. Johnson

Technical Program Manager

Agency for Nuclear Projects

State of Nevada

Evergreen Center, Suite 252

1802 N. Carson St.

Carson City, NV 89710

P. S. Justus

NRC Site Representative

301 E. Stewart Ave., Room 203

Las Vegas, NV 89101
No. of

Copies

H. N. Kalia

Project Leader for ESF Test

Coordination

Los Alamos National Laboratory

MS 527

101 Convention Center Drive, Suite 820

Las Vegas, NV 89101

M. Karakouzian

1751 E. Reno, \#125

Las Vegas, NV 89119

W. R. Keefer

U.S. Geological Survey

913 Federal Center

P.O. Box 25046

Denver, CO 80225

C. Kouts (RW-4)

Office of Strategic Planning and International Programs

OCRWM

U.S. Department of Energy

1000 Independence Avenue, S.W.

Washington, DC 20585

J. M. LaMonaca

Records Specialist

U.S. Geological Survey

421 Federal Center

P.O. Box 25046

Denver, CO 80225

R. Lance

INTERA, Inc.

6859 Austin Center Blvd.

Austin, TX 78731

Lander County Board of

Commissioners

315 South Humboldt Street

Battle Mountain, NV 89820 
No. of

Copies

D. Langmuir

Nuclear Waste Technical Review Board

109 S. Lookout Mountain Creek

Golden, CO 80401

3 Lawrence Berkeley National

Laboratory

Earth Sciences Division

1 Cyclotron Road

Berkeley, CA 94720

ATTN: K. Pruess

C. F. Tsang

J. Wang

5 Lawrence Livermore National Laboratory

University of California

P.O. Box 808

Livermore, CA 94550

ATTN: T. A. Busheck

W. L. Clarke

W. J. O'Connell

W. Halsey

L. Lewis

3 R. R. Loux, Executive Director Agency for Nuclear Projects

State of Nevada

Evergreen Center, Suite 252

1802 N. Carson St.

Carson City, NV 89710

F. Mariani

White Pine County Coordinator

P.O. Box 135

Ely, NV 89301

J. J. McKetta, Jr.

Nuclear Waste Technical Review Board Department of Chemical Engineering CPE Building

Austin, TX 78712
No. of

Copies

B. R. Mettham

Inyo County Yucca Mountain

Repository Assessment Office

P.O. Drawer L

Independence, CA 93526

R. A. Milner (RW-40)

Office of Storage and Transportation

OCRWM

U.S. Department of Energy

1000 Independence Avenue, S.W.

Washington, DC 20585

P. A. Niedzielski-Eichner

Nye County Nuclear Waste

Repository Project Office

P.O. Box 221274

Chantilly, VA 22022-1274

NRC Document Control Desk

Division of Waste Management

Nuclear Regulatory Commission

Washington, DC 20555

Nye County District Attorney

P.O. Box 593

Tonopah, NV 89049

W. Offutt

Nye County Manager

P.O. Box 153

Tonopah, NV 89049

ONWI Library

Battelle Columbus Laboratory

Office of Nuclear Waste Isolation 505 King Avenue

Columbus, $\mathrm{OH} 43201$

Distr.6 
No. of

Copies

G. J. Parker (RW-332)

Regulatory Policy and

Requirements Branch

OCRWM

U.S. Department of Energy

1000 Independence Avenue, S.W.

Washington, DC 20585

T. M. Pigford

Department of Nuclear Engineering

University of California

Berkeley, CA 94720

J. Pitts

Lincoln County Nuclear Waste

Project Office

P.O. Box 90

Pioche, NV 89043

V. E. Poe

Office of Nuclear Projects

Mineral County

P.O. Box 1600

Hawthorne, NV 89415

R. F. Pritchett

Technical Project Officer for YMP

Reynolds Electrical and

Engineering Co., Inc.

MS 408

P.O. Box 98521

Las Vegas, NV 89193-8521

4 V. F. Reich, Librarian

Nuclear Waste Technical Review Board 1100 Wilson Blvd., Suite 910

Arlington, VA 22209

L. Reiter

Nuclear Waste Technical Review Board

1100 Wilson Blvd., Suite 910

Arlington, VA 22209
No. of

Copies

Repository Licensing and Quality Assurance

Project Directorate

Division of Waste Management

U.S. Nuclear Regulatory Commission

Washington, DC 20555

D. Rhode

Desert Research Institute

P.O. Box 60220

Reno, NV 89506

J. Roberts (RW-33)

Director, Regulatory

Compliance Division

OCRWM

U.S. Department of Enersy

1000 Independence Avenue, S.W.

Washington, DC 20585

J. D. Saltzman (RW-2)

Acting Deputy Director

Office of Civilian Radioactive Waste Management

U.S. Department of Energy

1000 Independence Avenue, S.W.

Washington, DC 20585

4 Sandia National Laboratory

Department 6312

Albuquerque, NM 87185

ATTN: G. E. Barr

H. A. Dockery

M. A. Wilson

J. Gauthier

3 Sandia National Laboratory

Department 6313

Albuquerque, NM 87185

ATTN: R. W. Barnard

F. W. Bingham

T. E. Blejwas

Distr.7 
No. of Copies

Sandia National Laboratory

Department 1513

Albuquerque, NM 87185

ATTN: R. R. Eaton

J. H. Sass

Branch of Tectonophysics

U.S. Geological Survey

2255 N. Gemini Drive

Flagstaff, AZ 86001

The Honorable C. Schank

Chairman

Churchill County Board of

Commissioners

190 W. First St.

Fallon, NV 89406

V. R. Schneider

Assistant Chief Hydrologist

MS 414

Office of Program Coordination

and Technical Support

U.S. Geological Survey

12201 Sunrise Valley Drive

Reston, VA 22092

Senior Project Manager for

Yucca Mountain

Repository Project Branch

Division of Waste Management

U.S. Nuclear Regulatory Commission

Washington, DC 20555

D. Shelor (RW-30)

Office of Systems and

Compliance Division

OCRWM

U.S. Department of Energy

1000 Independence Avenue, S.W.

Washington, DC 20585
No. of

Copies

5 L. E. Shephard

Technical Project Officer for YMP

Sandia National Laboratories

Organization 6310

P.O. Box 5800

Albuquerque, NM 87185

L. M. Smith (RW-20)

Office of Geologic Disposal

Office of Civilian Radioactive

Waste Management

U.S. Department of Energy

1000 Independence Avenue, S. $\mathrm{h}^{\prime}$.

Washington, DC 20585

E. L. Snow, Program Manager

Roy F. Weston, Inc.

955 L'Enfant Plaza, S.W.

Washington, DC 20024

2 Southwest Research Institute

Center for Nuclear Waste

Regulatory Analyses

622 Culebra Road

San Antonio, TX 78228

ATTN: B. Sagar

J. Walton

J. S. Stuckless

Geologic Division Coordinator

MS 913

Yucca Mountain Project

U.S. Geological Survey

P.O. Box 25046

Denver, CO 80225

A. T. Tamura

Science and Technology Division

Office of Scientific and

Technical Information

U.S. Department of Energy

P.O. Box 62

Oak Ridge, TN 37831

Distr.8 
No. of

Copies

Technical Information Center

Roy F. Weston, Inc.

955 L'Enfant Plaza, S.W.

Washington, DC 20024

8 Technical Information Officer

DOE Nevada Operations Office

U.S. Department of Energy

P.O. Box 98518

Las Vegas, NV 89193-8518

C. Thistlethwaite, AICP

Associate Planner

Inyo County Planning

Department

Drawer L

Independence, CA 93526

$5 \quad$ U.S. Department of Energy

Yucca Mountain Site Characterization Project Office 101 Convention Center Drive Phase II, Suite 200

P.O. Box 98608

Las Vegas, NV 89193-8608

ATTN: J. M. Boak

J. R. Dyer

J. J. Lorenz

C. M. Newbury

A. M. Simmons

$7 \quad$ U.S. Department of Energy

1000 Independence Avenue, S.W.

Washington, DC 20585

ATTN: S. J. Brocoum (RW-22)

R. A. Milner (RW-332)

G. J. Parker (RW-322)

J. Roberts (RW-30)

J. Roberts (RW-j3)

S. Rousso (RW-50)

T. Wood (RW-52)
No. of

Copies

G. Van Roekel

Director of Community Development

City of Caliente

P.O. Box 158

Caliente, NV 89008

E. D. Verink

Nuclear Waste Technical Review Board

4401 N.W. 18th Place

Gainesville, FL 32605

M. D. Voegele

Technical Project Officer for YMP

SAIC, Inc.

101 Convention Center Drive

Suite 407

Las Vegas, NV 89109

D. Warner North

Nuclear Waste Technical Review Board

Decision Focus, Inc.

4984 El Camino Real

Los Altos, CA 94062

P. J. Weeden, Acting Director

Nuclear Radiation Assessment Division

U.S. Environmental Protection Agency

Environmental Monitoring

Systems Laboratory

P.O. Box 93478

Las Vegas, NV 89193-3478

C. L. West, Director

Office of External Affairs

DOE Nevada Operations Office

U.S. Department of Energy

P.O. Box 98518

Las Vegas, NV 89193-8518

R. Williams, Jr.

P.O. Box 16

Austin, NV 89310

Distr.9 
No. of Copies

T. Wood (RW-52)

Director, M\&O Management Division OCRWM

U.S. Department of Energy

1000 Independence Avenue, S.W.

Washington, DC 20585

Sherman S. C. Wu

Branch of Astrogeology

U.S. Geological Survey

2255 N. Gemini Drive

Flagstaff, AZ 86001

D. Zesiger

U.S. Geological Survey

101 Convention Center Drive

Suite 860, MS 509

Las Vegas, NV 89109

\section{FOREIGN}

Commission of the European

Communities

200 Rue de la Loi

B-1049 Brussells

BELGIUM

\section{ONSITE}

2 DOE Richland Operations Office

D. C. Langstaff

J. J. Sutey

K8-50

$\mathrm{K} 8-50$
No. of

Copies

34 Pacific Northwest Laboratory

M. J. Altenhofen K7-34

I. G. Choi K7-15

J. M. Cuta K7-15

R. E. Einziger P7-14

D. M. Elwood PORTL

D. W. Engel (5) K7-34

M. D. Erickson K7-02

P. W. Eslinger K6-52

G. I. Fann K7-15

J. A. Fort K7-15

W. J. Gray P7-14

K. S. Lessor K7-22

A. M. Liebetrau K7-34

N. J. Lombardo K7-02

B. P. McGrail K2-38

W. E. Nichols K6-77

E. W. Pearson K7-15

J. S. Roberts K7-15

F. M. Ryan K7-70

R. E. Westerman $\quad$ P8-44

R. E. Williford K2-44

M. D. White K7-15

P. D. Whitney K7-34

S. B. Yabusaki K6-77

Publishing Coordination

Technical Report Files (5) 

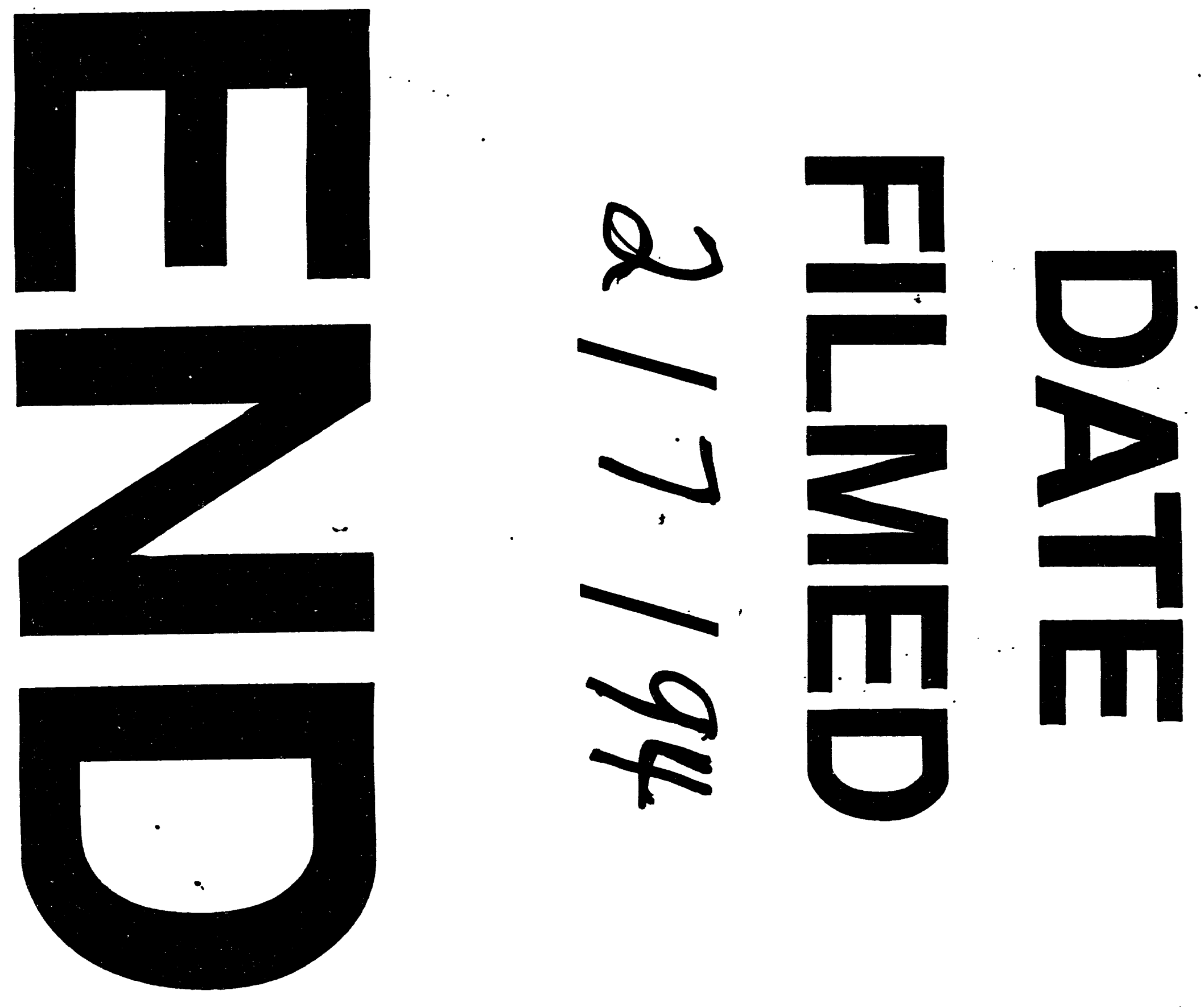
